DOE/ID-22201

Prepared in cooperation with the U.S. Department of Energy

\title{
Geostatistical Modeling of Sediment Abundance in a Heterogeneous Basalt Aquifer at the Idaho National Laboratory, Idaho
}

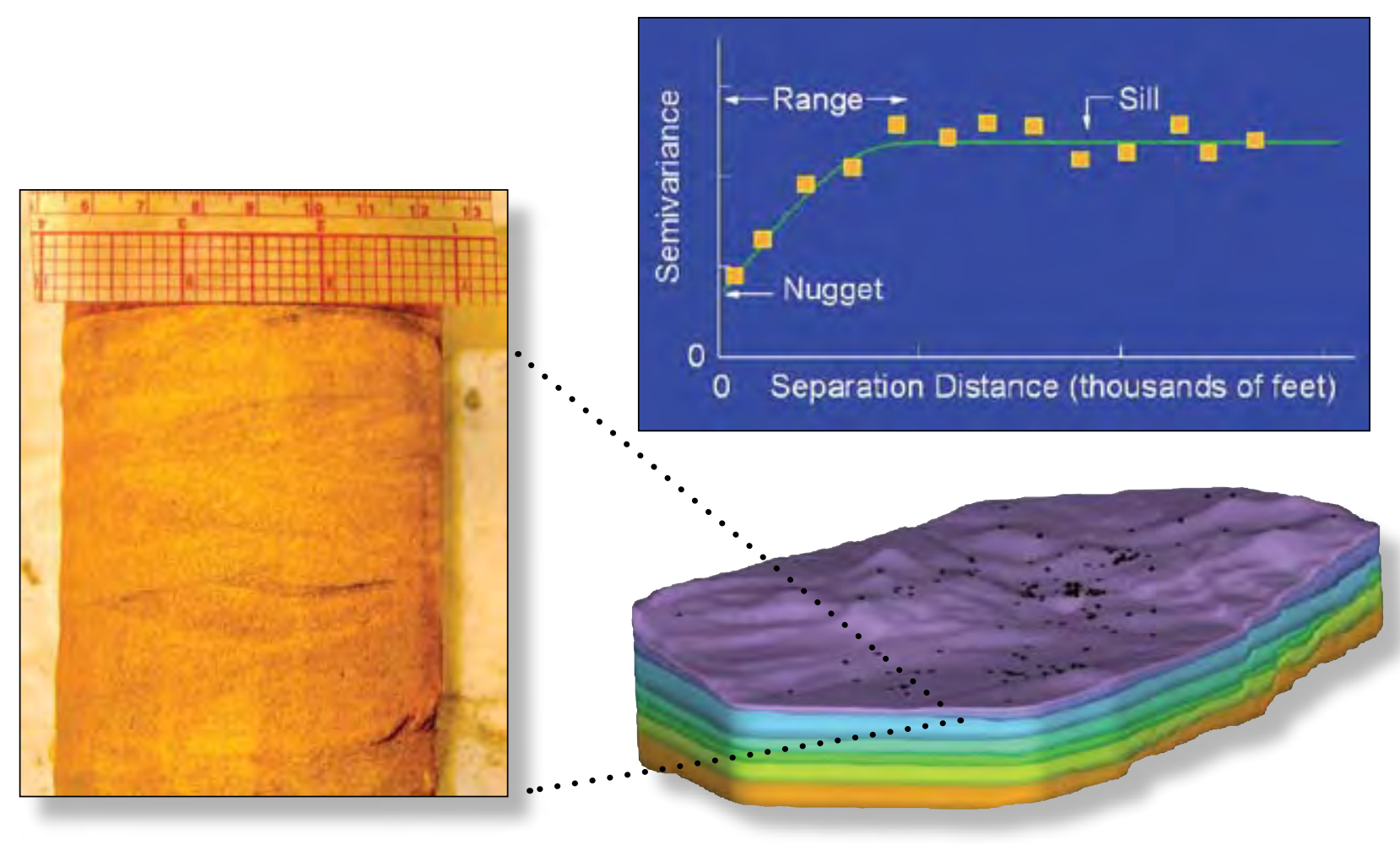

Scientific Investigations Report 2006-5316 



\section{Geostatistical Modeling of Sediment Abundance in a Heterogeneous Basalt Aquifer at the Idaho National Laboratory, Idaho}

By John A. Welhan, Idaho Geological Survey,

Renee L. Farabaugh, Department of Geosciences, Idaho State University, Melissa J. Merrick, Department of Geosciences, Idaho State University, and Steven R. Anderson, formerly with U.S. Geological Survey

Prepared in cooperation with the

U.S. Department of Energy DOE/ID-22201

Scientific Investigations Report 2006-5316 


\title{
U.S. Department of the Interior DIRK KEMPTHORNE, Secretary
}

\author{
U.S. Geological Survey \\ Mark D. Myers, Director
}

\section{U.S. Geological Survey, Reston, Virginia: 2007}

For product and ordering information:

World Wide Web: http://www.usgs.gov/pubprod

Telephone: 1-888-ASK-USGS

For more information on the USGS--the Federal source for science about the Earth, its natural and living resources, natural hazards, and the environment:

World Wide Web: http://www.usgs.gov

Telephone: 1-888-ASK-USGS

Any use of trade, product, or firm names is for descriptive purposes only and does not imply endorsement by the U.S. Government.

Although this report is in the public domain, permission must be secured from the individual copyright owners to reproduce any copyrighted materials contained within this report.

Suggested citation:

Welhan, J.A., Farabaugh, R.L., Merrick, M.J., and Anderson, S.R., 2007, Geostatistical modeling of sediment abundance in a heterogeneous basalt aquifer at the Idaho National Laboratory, Idaho: U.S. Geological Survey Scientific Investigations Report 2006-5316, 32 p. 


\section{Contents}

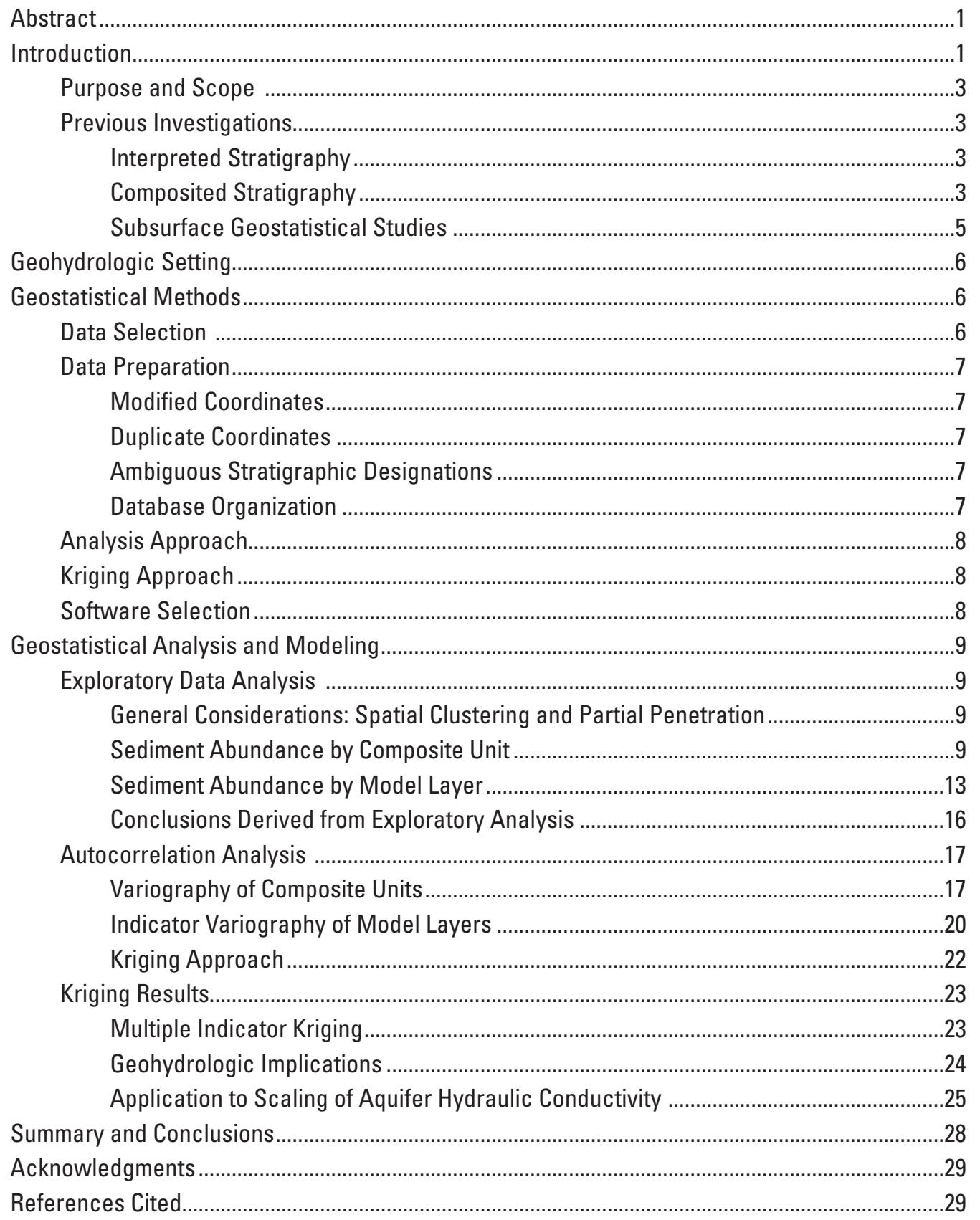




\section{Figures}

Figure 1. Map showing study area, major topographic features, ground-water flow model extent, and locations of borehole data used for this analysis in and near the Idaho National Laboratory, Idaho

Figure 2. Map showing principal volcanic, structural, and geologic features in the study area, showing the inferred location of the Big Lost Trough in relation to major volcanic constructional zones....

Figure 3. Diagram showing cross section $A$ - $A$ ' showing composite stratigraphic units 1 through 14, ground-water model layers $A$ through $F$, and the relation between model layers and actual stratigraphy

Figure 4. Maps showing geographic distribution of sediment-rich and sediment-poor boreholes that fully penetrate composite stratigraphic units 1 through 7 and 8 through 14, as defined by Anderson and Liszewski (1997)

Figure 5. Graphs showing comparative distributions of sediment abundances showing the effect of spatial clustering on summary statistics

Figure 6. Box plots distribution of thickness of total accumulated sediment in boreholes that fully penetrate individual composite units 1 through 7 and in boreholes that penetrate the oldest units 8 to 14 combined

Figure 7. Histograms showing sediment abundance in each of composite units 1 through 7 and in combined unit 8 to 14 , as a percentage of composite unit thickness

Figure 8. Histograms showing distributions of sediment percentage in various groupings of composite units showing evidence of statistical similarity among the youngest (other than composite unit 1) and the oldest

Figure 9. Histograms showing distributions of total sediment thickness among various groupings of composite units

Figure 10. Maps showing availability of boreholes that fully penetrate each model layer and that were used to model the two-dimensional spatial abundance of sediment in each model layer

Figure 11. Histograms showing distributions of sediment percentages in boreholes that fully penetrate layers $A, B$, and $C$, showing similar distributions, and in the unsaturated zone (layer $\mathrm{U}$ ), which has a substantially different distribution because of the influence of composite unit 1

Figure 12. Histograms showing distributions of sediment percentage from fully penetrating wells in model layers A, B, and C in different areas north and south of the stratigraphic discontinuity and among clustered and nonclustered areas shown in figure 10

Figure 13. Relative variograms of sediment thickness within composite units 1 through 6 , based on the inverted correlogram statistic

Figure 14. Graphs showing cumulative frequency distributions (CFDs) of sediment percentage in boreholes that fully penetrate layers $A, B$, and C showing CFD probabilities calculated from equation 1 


\section{Figures-Continued}

Figure 15. Graphs showing examples of multiple indicator semivariograms at selected thresholds for layer $A$, showing the nature of the autocorrelation structure and the progressive change in nuggets, sills, and ranges as thresholds increase ..... 21

Figure 16. Graph showing results of multiple indicator variogram analysis for layer A, showing the progressive change in autocorrelation structure across a range of indicator thresholds

Figure 17. Maps showing median percentage of sediment derived from multiple indicator kriging of layers $A, B$, and $C$. Percentages are equivalent to thickness, in feet, within each 100-foot thick layer

Figure 18. Map showing ordinary kriging variance $\left(\sigma_{\mathrm{OK}}^{2}\right)$ in layers $A, B$, and $C$, reflecting the relative uncertainty of kriging estimates based on the availability and arrangement of borehole data

Figure 19. Maps showing distribution of sediment-rich and sediment-poor areas in the model domain

Figure 20. Graph and map showing comparison of local cumulative frequency distributions (CFDs) derived from multiple indicator kriging (mIK) at two locations in Layer $A$, representing locations with low (location 1) and high (location 2) estimation variance

Figure 21. Maps showing zones of hydraulic conductivity estimated from the kriged sediment content in layer A

Figure 22. Map showing layer A's bulk hydraulic conductivity $\left(K_{\text {bulk }}\right)$ classified according to the relative confidence in the kriged estimates as defined by the ordinary kriging variance

\section{Tables}

Table 1. Summary of composite stratigraphic units, thicknesses, and time spans as defined by Anderson and Liszewski (1997) and used in this study. ...

Table 2. Results of nonparametric tests of similarity of median sediment content between various groupings of younger and older composite units, where sediment content is expressed in percent.

Table 3. Results of nonparametric tests of similarity of median sediment content between groups of younger and older composite units, where sediment content is expressed as sediment thickness. 


\section{Conversion Factors, Datums, Abbreviations, and Acronyms}

Conversion Factors

\begin{tabular}{lll}
\hline Multiply & \multicolumn{1}{c}{ By } & To obtain \\
\hline cubic foot $\left(\mathrm{ft}^{3}\right)$ & 0.02832 & cubic meter \\
cubic mile $\left(\mathrm{mi}^{3}\right)$ & 4.168 & cubic kilometer \\
foot $(\mathrm{ft})$ & 0.3048 & meter \\
foot per day $(\mathrm{ft} / \mathrm{d})$ & 0.3048 & meter per day \\
foot squared per day $\left(\mathrm{ft}^{2} / \mathrm{d}\right)$ & 0.09290 & meter squared per day \\
gallon $(\mathrm{gal})$ & 0.003785 & cubic meter \\
gallon per minute per foot $[(\mathrm{gal} / \mathrm{min}) / \mathrm{ft})]$ & 0.2070 & liter per second per meter \\
mile $(\mathrm{mi})$ & 1.609 & kilometer \\
square foot $\left(\mathrm{ft}^{2}\right)$ & 0.09290 & square meter \\
square mile $\left(\mathrm{mi}^{2}\right)$ & 2.590 & square kilometer \\
\hline
\end{tabular}

Temperature in degrees Celsius $\left({ }^{\circ} \mathrm{C}\right)$ may be converted to degrees Fahrenheit $\left({ }^{\circ} \mathrm{F}\right)$ as follows:

$$
{ }^{\circ} \mathrm{F}=\left(1.8 x^{\circ} \mathrm{C}\right)+32
$$

Temperature in degrees Fahrenheit $\left({ }^{\circ} \mathrm{F}\right)$ may be converted to degrees Celsius $\left({ }^{\circ} \mathrm{C}\right)$ as follows:

$$
{ }^{\circ} \mathrm{C}=\left({ }^{\circ} \mathrm{F}-32\right) / 1.8
$$

Datums

Vertical coordinate information is referenced to the National Geodetic Vertical Datum of 1929 (NGVD 29).

Horizontal coordinate information is referenced to the North American Datum of 1927 (NAD 27).

Altitude, as used in this report, refers to distance above the vertical datum.

*Transmissivity: The standard unit for transmissivity is cubic foot per day per square foot times foot of aquifer thickness [(ft $\left.\left.\mathrm{ft}^{3} \mathrm{~d}\right) / \mathrm{ft}^{2}\right] \mathrm{ft}$. In this report, the mathematically reduced form, foot squared per day $\left(\mathrm{ft}^{2} / \mathrm{d}\right)$, is used for convenience.

Abbreviations and Acronyms

\begin{tabular}{ll}
\hline Acronyms & \multicolumn{1}{c}{ Definition } \\
\hline C.U. & Composite stratigraphic unit \\
CFD & Cumulative frequency distribution \\
ESRP & Eastern Snake River Plain \\
GIS & Geographic Information System \\
GPS & Ground Positioning System \\
GSLIB & Geostatistical Software Library \\
INL & Idaho National Laboratory \\
K & Hydraulic conductivity \\
Ka & Thousand years \\
mIK & Multiple indicator kriging \\
RWMC & Radioactive Waste Management Complex \\
TAN & Test Area North \\
USGS & U.S. Geological Survey \\
\hline
\end{tabular}




\title{
Geostatistical Modeling of Sediment Abundance in a Heterogeneous Basalt Aquifer at the Idaho National Laboratory, Idaho
}

\author{
By John A. Welhan', Renee L. Farabaugh'², Melissa J. Merrick², and Steven R. Anderson ${ }^{3}$
}

\section{Abstract}

The spatial distribution of sediment in the eastern Snake River Plain aquifer was evaluated and modeled to improve the parameterization of hydraulic conductivity $(K)$ for a subregional-scale ground-water flow model being developed by the U.S. Geological Survey. The aquifer is hosted within a layered series of permeable basalts within which intercalated beds of fine-grained sediment constitute local confining units. These sediments have $K$ values as much as six orders of magnitude lower than the most permeable basalt, and previous flow-model calibrations have shown that hydraulic conductivity is sensitive to the proportion of intercalated sediment.

Stratigraphic data in the form of sediment thicknesses from 333 boreholes in and around the Idaho National Laboratory were evaluated as grouped subsets of lithologic units (composite units) corresponding to their relative timestratigraphic position. The results indicate that median sediment abundances of the stratigraphic units below the water table are statistically invariant (stationary) in a spatial sense and provide evidence of stationarity across geologic time, as well. Based on these results, the borehole data were kriged as two-dimensional spatial data sets representing the sediment content of the layers that discretize the ground-water flow model in the uppermost 300 feet of the aquifer.

Multiple indicator kriging (mIK) was used to model the geographic distribution of median sediment abundance within each layer by defining the local cumulative frequency distribution (CFD) of sediment via indicator variograms defined at multiple thresholds. The mIK approach is superior to ordinary kriging because it provides a statistically best estimate of sediment abundance (the local median) drawn from the distribution of local borehole data, independent of any assumption of normality. A methodology is proposed

\footnotetext{
${ }^{1}$ Idaho Geological Survey, Department of Geosciences, Idaho State University, Pocatello, Idaho 83209.

2 Department of Geosciences, Idaho State University, Pocatello, Idaho 83209 .

${ }^{3}$ Formerly with U.S. Geological Survey, Idaho National Laboratory Project Office, P.O. Box 2230, Idaho Falls, Idaho 93403.
}

for delineating and constraining the assignment of hydraulic conductivity zones for parameter estimation, based on the locally estimated CFDs and relative kriging uncertainty. A kriging-based methodology improves the spatial resolution of hydraulic property zones that can be considered during parameter estimation and should improve calibration performance and sensitivity by more accurately reflecting the nuances of sediment distribution within the aquifer.

\section{Introduction}

Idaho's largest fresh water resource, the Eastern Snake River Plain (ESRP) aquifer, occurs in the ESRP mafic volcanic province. This aquifer is composed primarily of pahoehoe basalt with intercalated sediments and minor occurrences of andesite and rhyolite. It is characterized by transmissivities and hydraulic conductivities ranging over six orders of magnitude and linear ground-water flow velocities up to $10 \mathrm{ft} / \mathrm{d}$ (Ackerman, 1991; Anderson and others, 1999).

A large number of well borings, logging records, and cores have been collected in the vicinity of the Idaho National Laboratory (INL) for defining the geohydrologic regime in this part of the ESRP aquifer (fig. 1). Improvements in characterization of the subsurface stratigraphy have led to increasingly sophisticated conceptual and digital models of the aquifer and of ground-water flow and transport at various spatial scales. A subregional-scale flow model (about $25 \times$ $75 \mathrm{mi}$; see fig. 1) currently is being tested and refined at the U.S. Geological Survey-INL (USGS-INL) project office. Calibration of the model has shown that assigned hydraulic conductivity values are sensitive to the relative abundance of sediment within the aquifer and that a more realistic model of the spatial variability of sediment will be required to refine the flow simulator. 


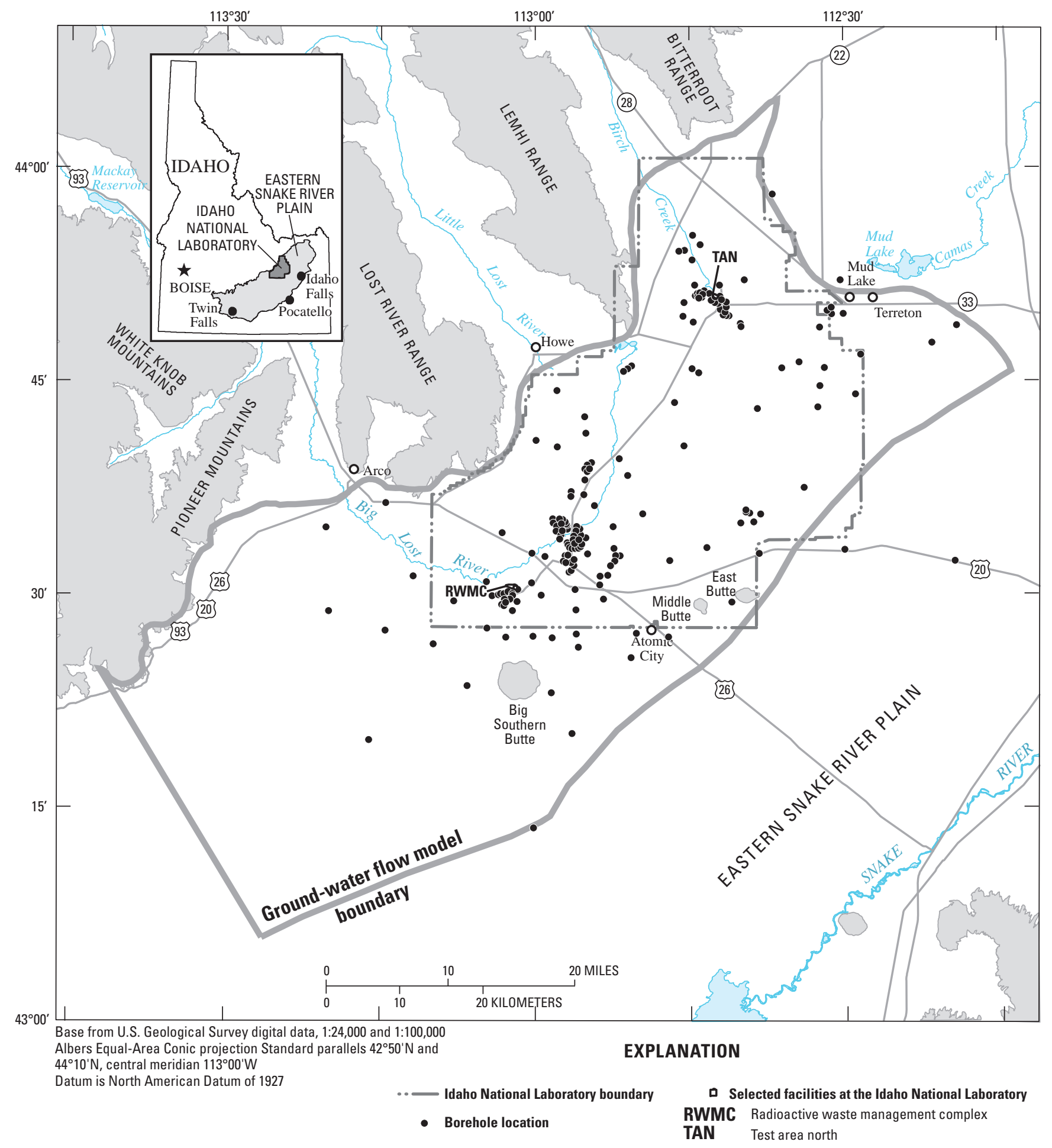

Figure 1. Study area, major topographic features, ground-water flow model extent, and locations of borehole data used for this analysis in and near the Idaho National Laboratory, Idaho. 


\section{Purpose and Scope}

This study, conducted by the USGS in cooperation with the U.S. Department of Energy, was undertaken to develop a geostatistical model of sediment abundance in the aquifer that can be used to constrain future ground-water flow model calibrations.

The spatial model of sediment abundance is based on borehole data compiled by Anderson and others (1996) in a region of the ESRP corresponding to the geographic extent of the ground-water model (fig. 1). The sediment model was created in a Geographic Information Systems (GIS)-compliant format that can interface with the ground-water flow model on a cell-by-cell basis, in specific depth-discretized layers corresponding to the digital flow model. The relative uncertainty of the sediment abundance estimates also had to be computed on a cell-by-cell basis because the degree of borehole coverage over the model domain is relatively sparse and highly variable. Geostatistical methods were employed to analyze the borehole data to select and justify an appropriate estimation method (in this case, multiple indicator kriging) and to quantify the relative uncertainty of the resulting estimates. Finally, the sediment model was used to demonstrate an approach by which sediment abundances could be used to develop a refined calibration process for the ground-water model.

\section{Previous Investigations}

Hundreds of boreholes have been drilled in and near the INL during the past 50 years for purposes of characterizing the ESRP aquifer and monitoring chemical and radioactive wastes in the subsurface. The lithologies encountered in most of these boreholes have been characterized using geophysical logging techniques; less than 10 percent of all boreholes have been cored and selectively analyzed for properties such as geochronology, paleomagnetism, and bulk geochemistry in an ongoing attempt to characterize subsurface architecture. Systematic interpretation of these and other data sets has led to the development of a stratigraphic framework (for example, Anderson and others, 1996) and conceptual models of the aquifer (Lindholm and Vaccaro, 1988; Ackerman and others, 2006), without which the quantitative analysis undertaken in this study would not be possible.

\section{Interpreted Stratigraphy}

Walker (1974) conducted one of the earliest stratigraphic studies of the INL's subsurface using a combination of geologic and geophysical logs. His work was followed by another at the Radioactive Waste Management Complex
(RWMC) in which sedimentary interbeds and individual basalt-flow groups (defined as packages of flows derived from a single shield volcano) were differentiated using natural-gamma logs (Barraclough and others, 1976). The first quantitative stratigraphic study using continuous cores was conducted at the RWMC using Potassium-Argon (K-Ar) age dating, paleomagnetic polarity and inclination measurements, and petrographic characterization (Kuntz and others, 1980). Similar studies in other areas have used ${ }^{40} \mathrm{Argon} /{ }^{39} \mathrm{Argon}$ and $\mathrm{K}$-Ar ages (Champion and others, 1988; Lanphere and others, 1993, 1994; Champion and Lanphere, 1997; Champion and Herman, 2003). Detailed, small-scale stratigraphic interpretations based on basalt chemistry have been described by Reed and others (1997), Scarberry (2003), and Grimm Chadwick (2004) for selected coreholes.

The work of Anderson and coworkers (Anderson and Lewis, 1989; Anderson, 1991; Anderson and Bowers, 1995; Anderson and Bartholomay, 1995) created the first and most carefully documented and vetted compilation of subsurface lithologic variability and stratigraphic correlations across the INL. Starting at selected INL facilities, their work with natural-gamma log records that had been calibrated to available core properties, led them to eventually describe and compile a subsurface stratigraphic database of 333 boreholes across the INL and vicinity (Anderson and others, 1996; Anderson and Liszewski, 1997). This database constitutes the basis of this study; the geographic locations of its boreholes are shown in figure 1.

\section{Composited Stratigraphy}

The database compiled by Anderson and others (1996) indicates that boreholes that penetrate the unsaturated zone of the aquifer have penetrated at least 178 identified basalt-flow groups, 103 sedimentary interbeds, 6 andesite-flow groups, and 4 rhyolite domes. Anderson and Liszewski (1997) first proposed a classification based on groups of units of similar age that was intended to show the principal stratigraphic features in the subsurface. They grouped individual basalt and sedimentary units into 14 composite stratigraphic units, each made up of 5 to 90 individual units.

Table 1 summarizes these composite stratigraphic units. Composite unit 1, the youngest, is made up of 78 basalt-flow groups and 12 sedimentary interbeds. Composite unit 14, the oldest, is made up of only four identified basalt-flow groups and one sedimentary interbed. The decreasing number of individual units in successively older composite units may be due to larger and less-frequent volcanic eruptions as well as to the decreasing availability of borehole data with depth on which to base stratigraphic correlations. 
Table 1. Summary of composite stratigraphic units, thicknesses, and time spans as defined by Anderson and Liszewski (1997) and used in this study.

[Abbreviations: $\mathrm{ft}$, foot; Ka, thousands of years; n.a., not applicable]

\begin{tabular}{cccc}
\hline $\begin{array}{c}\text { Composite } \\
\text { stratigraphic } \\
\text { unit name }\end{array}$ & $\begin{array}{c}\text { Number of } \\
\text { wells fully } \\
\text { penetrating } \\
\text { the unit }\end{array}$ & $\begin{array}{c}\text { Average } \\
\text { thickness of } \\
\text { the unit } \\
\text { (ft) }\end{array}$ & $\begin{array}{c}\text { Approximate } \\
\text { time span of } \\
\text { the unit } \\
\text { (Ka) }\end{array}$ \\
\hline 1 & 300 & 62 & $5-250$ \\
2 & 170 & 108 & $250-350$ \\
3 & 140 & 163 & $350-440$ \\
4 & 143 & 137 & $440-515$ \\
5 & 112 & 126 & $515-580$ \\
6 & 68 & 107 & $580-650$ \\
7 & 13 & 283 & $650-800$ \\
$8-14$ & n.a. & n.a. & $800-1,800$ \\
\hline
\end{tabular}

Composite units 1 through 7 represent time spans of approximately 65 to 248 thousand years each and, collectively, 800 thousand years. Composite units 1, 2, and 3 generally comprise most of the unsaturated zone and only units 4 and older influence saturated ground-water flow in the aquifer. Composite units 8 through 14 span an age range of about 800 thousand to 1.8 million years and are grouped together as one aggregated composite unit. As shown by Anderson and others (1996) and by subsequent work, these older units occur beneath most of the INL at considerable depths below the water table. In the northeastern part of the INL, however, where a stratigraphic discontinuity exposes the older units at the surface, they make up most or all of the unsaturated zone.

The approximate locus of the stratigraphic discontinuity is shown in figure 2, and its subsurface character is shown in figure 3 , together with the nomenclature used to identify the layers that discretize the aquifer in the subregional ground-water flow model. The water table in figure 3 reflects hydrologic conditions in 1996, at which time composite unit 5 was generally below the water table south of the discontinuity, whereas north of it, only composite units 12 and older coincided with saturated conditions (Anderson and Liszewski, 1997). Despite recent drought conditions, a similar geohydrologic situation to that shown in figure 3 prevailed in 2004.

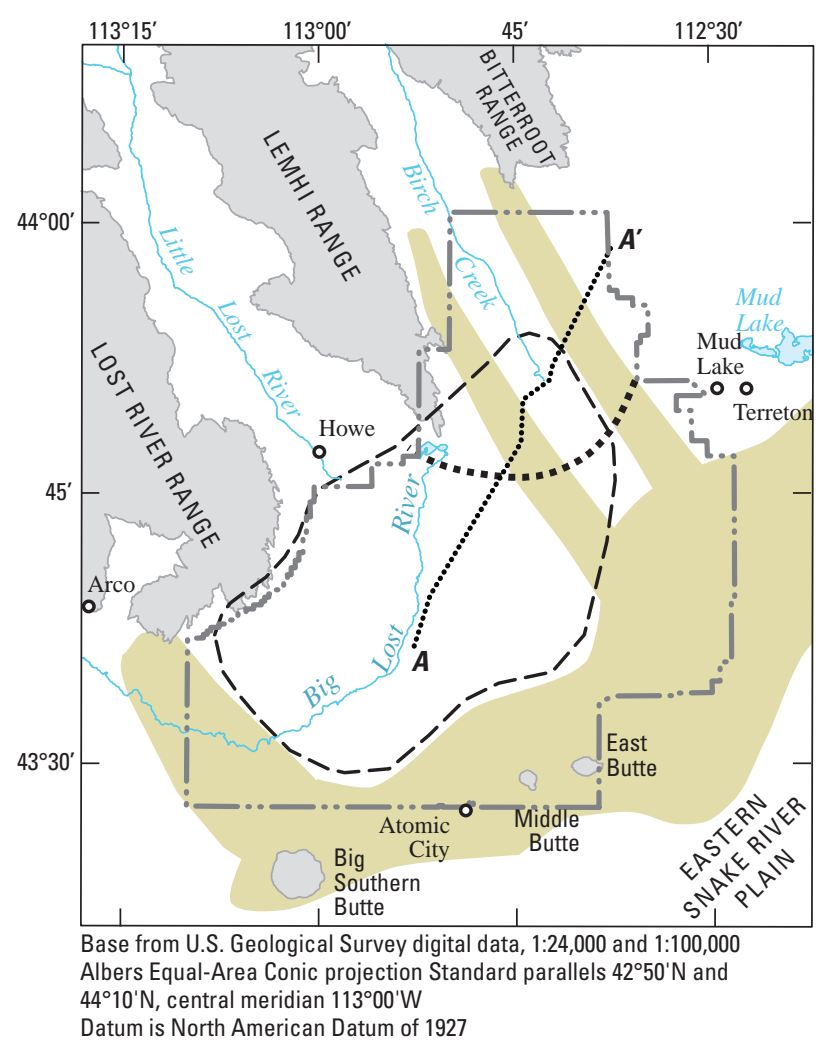

\section{EXPLANATION}

Axial volcanic high and rift zones-From Geslin and others, 1999

Approximate location of stratigraphic discontinuity-From Anderson and Liszewski, 1997

- - Approximate extent of Big Lost Trough—From Geslin and others, 1999

A

Trace of section-See figure 3

Idaho National Laboratory boundary

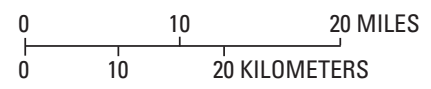

Figure 2. Principal volcanic, structural, and geologic features in the study area, showing the inferred location of the Big Lost Trough in relation to major volcanic constructional zones. 


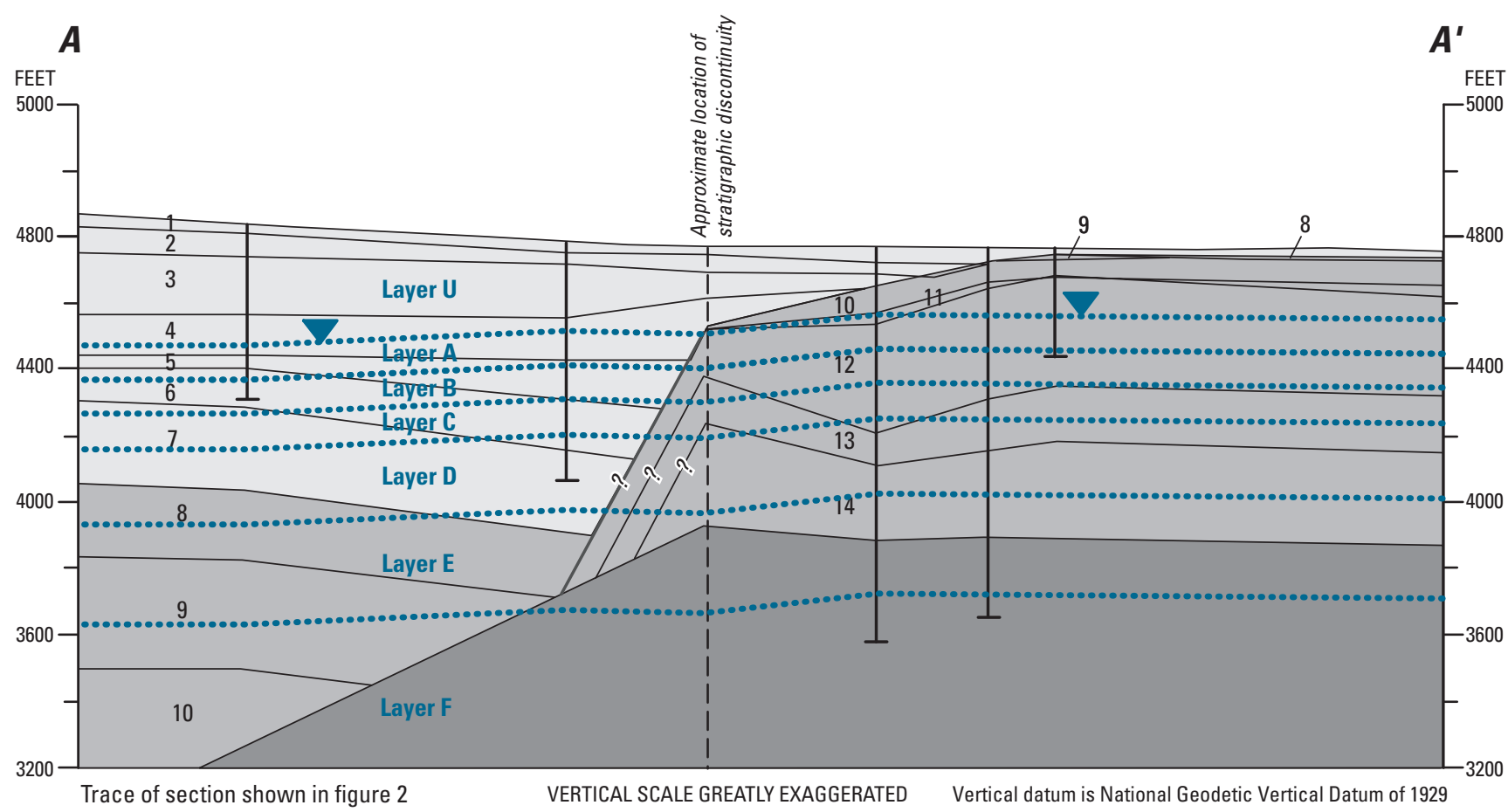

EXPLANATION

3 Stratigraphic unit-age range per layer with layer number-See table 1

Less than 800,000 years

$800,000-1,800,000$ years

Undifferentiated basalts and sediments

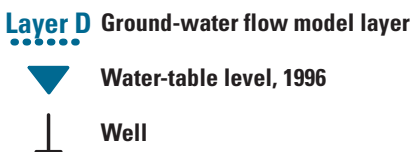

$\perp$ Well

Figure 3. Cross section $A-A^{\prime}$ showing composite stratigraphic units 1 through 14 , ground-water model layers $A$ through $\mathrm{F}$, and the relation between model layers and actual stratigraphy. Modified from Anderson and Liszewski (1997).

\section{Subsurface Geostatistical Studies}

Inferring spatial continuity is one of the principal goals of geostatistics. Spatial autocorrelation is a statistical property that characterizes the statistical similarity of measurements separated by various distances. Various types of autocorrelation statistics known as variogram statistics can be used to describe the degree of similarity in space as well as to constrain geostatistical predictive models to make optimal estimates at unsampled locations (as well as quantify estimation uncertainty). Previous geostatistical work at the INL has demonstrated that subsurface lithologic properties in the ESRP aquifer are characterized by moderate to strong spatial autocorrelation, with greater statistical similarity over short distances that diminishes with distance. This fact can be exploited through various geostatistical modeling techniques (for example, kriging) to make best unbiased estimates of subsurface properties at unsampled locations. Previous geostatistical analysis of borehole data at the INL has been conducted with one of two general aims: (1) characterizing the nature of subsurface hydrologic variability (Welhan and Reed, 1997); and (2) modeling spatial variability to predict subsurface lithologic or hydrologic properties (Welhan and others, 2002a; Leecaster, 2002, 2004).

In previous geostatistical modeling at the INL, different approaches have been used to achieve different goals. Welhan and others (2002a) used a stochastic indicator simulator to model the spatial configuration of sediments and basalt interflow zones in the aquifer beneath the Test Area North, Leecaster $(2002,2004)$ applied ordinary kriging to predict sedimentary interbed thicknesses and subsurface hydraulic properties of the aquifer in an area beneath the RWMC, and Gego and others (2002) used sequential Gaussian simulation to cast particle transport and breakthrough times in a stochastic context and demonstrate the application of probabilistic (Monte Carlo) ground-water modeling methods. 


\section{Geohydrologic Setting}

The ESRP is an elongate, downwarped basin containing approximately 3,500 ft of Quaternary and late Tertiary basalt lava flows and sedimentary interbeds overlying late Tertiary rhyolitic volcanic rocks. The basin is characterized by plainsstyle volcanism (Greeley, 1982) comprising thin (3-100 ft), basaltic, pahoehoe lava flows and coalesced shield volcanoes. Estimates of basalt accumulation rates and eruptive recurrence intervals in 23 boreholes across the INL were published by Champion and others (2002). An analysis of their data reveals that accumulation rates are normally distributed, with pre- $800 \mathrm{Ka}$ (thousand years) basalts having a higher mean accumulation rate than post- $800 \mathrm{Ka}$ basalts $(125 \mathrm{ft} / \mathrm{Ka}$ versus $79 \mathrm{ft} / \mathrm{Ka}) .{ }^{4}$ Recurrence intervals are lognormally distributed with a $\pm 1 \sigma$ interval about the median of 66 [33-167] Ka, and pre- $800 \mathrm{Ka}$ basalts have a shorter median recurrence interval than post- $800 \mathrm{Ka}$ basalts (54 Ka versus $100 \mathrm{Ka}$ ). ${ }^{5}$

Basalt lava flows are highly fractured at their margins, less so in their interiors, and the rubbly contacts between individual flows (interflow zones) can have greatly enhanced porosity and permeability that focuses ground-water movement (Lindholm and Vaccaro, 1988). The morphology and stacking of lava flows imparts a complex, anastomosed hydrostratigraphy of preferred flow paths at the local scale and a subhorizontal stratigraphic character at larger scales (Welhan and others, 2002b).

Lengthy periods of quiescence during volcanic construction were marked by accumulation of fine-grained eolian, playa, and lacustrine sediment, and lesser amounts of coarser, channelized fluvial deposits within the basalt pile. Beneath the Idaho National Laboratory, sedimentary interbeds constitute about 15 percent by volume of the Snake River Plain aquifer and its unsaturated zone (Anderson and Liszewski, 1997). Because most interbeds are fine-grained, the presence of sediment in the subsurface tends to reduce the aquifer's bulk hydraulic conductivity. The amount of sediment penetrated by individual boreholes ranges from less than 5 percent of the stratigraphic column to more than 50 percent (up to 100 percent in shallow wells) near the terminus of the Big Lost and Little Lost Rivers in an inferred depositional center known as the Big Lost Trough (Anderson and others, 1996; Geslin and others, 1999).

The Big Lost Trough is situated between the Axial Volcanic Zone to the east, the mountains and associated valleys of the Basin and Range to the north, and the northwesttrending volcanic rift zones in the northern and southern parts

\footnotetext{
${ }^{4}$ Significant at a 95 percent confidence level; a Student's-t test of similarity of the mean accumulation rates returned a $p$-value of 0.017 (for pre- and post800 thousand year basalt sample sizes of 5 and 18 , respectively.

${ }^{5}$ Significant at a 99.9 percent confidence level; a Mann-Whitney rank-sum test of similarity of the median recurrence intervals returned a $p$-value of 0.0006 (for pre- and post- 800 thousand year basalt sample sizes of 13 and 80 , respectively).
}

of the INL (fig. 2). The Axial Volcanic Zone is a topographic high of linearly clustered volcanic vents that have shed numerous basalt flows towards the northwest and southeast. Over time, these lava flows interfingered with, and trapped, sediments carried onto the Snake River Plain by the Big Lost and Little Lost Rivers. Similar clusters of volcanic vents associated with the northwest-trending rift zones may have further confined the geographic extent of this depositional center.

Although volcanic construction likely exerts the primary control on local geomorphology and the development of depositional centers, it is unclear whether and to what extent regional tectonic subsidence influences larger-scale patterns of sedimentary and volcanic accumulation. Paleomagnetic and radiometric evidence suggests that the overall rate of basalt accumulation in the vicinity of the INL decreased about 200 Ka before present (Anderson and others, 1997; Champion and others, 2002). This conjecture explains the increased proportion of sediment in the stratigraphic section over the latter half of the Quaternary, but leaves unanswered the question of whether sediment supply rates and (or) sources also changed.

Of particular significance to this study is the stratigraphic discontinuity between older and younger stratigraphic units in the northernmost part of the INL (figs. 2 and $\underline{3}$ ). South of the discontinuity, rocks and sediments younger than about $800 \mathrm{Ka}$ overlie older units, dipping northeastward into the discontinuity; north of the discontinuity, these younger units are almost completely absent. Because different patterns and frequency of sediment accumulation may characterize the older and younger composite units, the statistical nature of their sediment distribution was investigated to determine if units had to be segregated and modeled separately.

\section{Geostatistical Methods}

Geostatistics is a specialized branch of statistical analysis concerned with the spatial relationships among data situated in two- or three-dimensional coordinate space. The process of geostatistical analysis and modeling includes: (1) assembling the data for analysis (data preparation); (2) calculating basic statistics, evaluating statistical stationarity, and performing data transformations to reduce the effect of outliers (exploratory analysis); (3) characterizing the spatial nature of the data (autocorrelation analysis); and (4) applying these statistical insights to create a model of spatial variability using a kriging estimator.

\section{Data Selection}

The database of basalt and interbed stratigraphy compiled by Anderson and others (1996) was used as the basis for this work. However, several limitations in their data set had to be addressed prior to analysis. Foremost was the fact that 
their stratigraphic interpretations represented best available knowledge at the time of compilation. Subsequent drilling, coring, and paleomagnetic and radiometric measurements have added to our understanding of subsurface stratigraphy beneath the INL. In many locations, new data have corroborated their interpretations; in other locations, new data have forced a re-evaluation of local stratigraphic relationships.

Such limitations do not diminish the value of the 1996 compilation for two reasons. First, the 1996 database defines the spatial occurrences of various lithologies, regardless of their interpreted stratigraphic context; therefore, the Anderson database represents a valid snapshot of subsurface sedimentary abundances at the time of data compilation. Second, as new subsurface data accrue, an appropriate temporal reference point will have to be selected on which future data syntheses can build. Although recent stratigraphic compilations were and currently are being made by various groups at the INL, these are not as extensively documented or vetted as the interpretations published by Anderson and coworkers. However, such compilations will provide a useful means of evaluating the accuracy and quality of earlier compilations after selecting an appropriate reference against which new information can be compared.

For these reasons, the database of Anderson and others (1996) serves as a reasonable baseline for analyzing the subsurface distribution of sediment in the study area. Geostatistical analysis and modeling performed during the current work did not rely on the interpreted stratigraphy of Anderson and others (1996) except as it was used by Anderson and Liszewski (1997) to assign a composite unit stratigraphy.

\section{Data Preparation}

The stratigraphic data set compiled by Anderson and others (1996) was in the form of a series of ASCII text files containing well locations, boring identifiers, lithologies, and interpreted stratigraphic unit designations. These were converted to spreadsheet form and then to .dbf tables, and ultimately incorporated in a relational database.

Several factors influenced the decision regarding which data fields to incorporate in the database tables. Relational queries were used to extract information for specific analysis tasks, and the information was reformatted to be compatible with different graphical display and visualization software, as well as with Geographic Information System (GIS) and geostatistical software used in subsequent analyses. Accordingly, database fields were assigned, containing modified identifiers with which data can be located by lithologic and stratigraphic codes and, in the future, to trace the pedigree of interpreted stratigraphic assignments. Appropriate coordinates were added, reflecting the USGS subregional ground-water flow-model domain, and various modifications were carried out, including removing duplicate coordinates, assigning missing-value flags, and modifying anomalous stratigraphic designations which, in their original form, were incompatible with the software used for graphical display and visualization. These modifications are described below.

\section{Modified Coordinates}

Anderson and others (1996) reported their well locations in geographic coordinates of latitude and longitude, as decimal degrees. To be compatible with the USGS subregional flow model, Albers (NAD 27) coordinates for all wells were provided by L. Davis (U.S. Geological Survey, written commun., 2004) and used to update the Anderson database. Altitude coordinates, originally referenced to the National Geodetic Vertical Datum of 1929 (NGVD 29), were not updated from those provided by Anderson and others (1996).

\section{Duplicate Coordinates}

A total of 12 pairs, triplets, and quadruplets of well locations in the original Anderson data set shared identical geographic coordinates, which usually reflects wells that were drilled close together. These locations were updated with more accurate Global Positioning System (GPS) coordinates provided by L. Davis (U.S. Geological Survey, written commun., 2004).

\section{Ambiguous Stratigraphic Designations}

The stratigraphic assignments made in the original database contain almost two dozen instances of a sedimentary unit interpreted to be a lens within a basalt unit; for example, the "B(1)s" sedimentary unit appears between two occurrences of the basalt unit "B(1)b". Such a designation is physically impossible unless the basalt unit is actually an aggregate of two or more separate basalt flows. These designations had to be corrected to avoid incompatibility with the visualization software used. Omission of such lenses was considered inappropriate, as was assigning different stratigraphic designations to the basalt above and below the lens (which would affect the entire database). The solution was to aggregate the thickness of the sedimentary lens with its stratigraphically nearest interbed. This approach introduced the least disruption into the modified database while preserving the lens's contribution to total sediment abundance.

\section{Database Organization}

To facilitate organization and data-query capabilities, a number of minor modifications were made to the original data set published by Anderson and others (1996). Some borehole names were modified, usually by deleting spaces or other ambiguous alphanumeric designators, to ensure standardized 
well names for linking tables. A field was added to designate the composite unit into which a particular stratigraphic unit falls (table 1). Finally, a field was incorporated to allow for future changes to the interpreted stratigraphic assignments to track the "pedigree" of future stratigraphic interpretations and database modifications.

\section{Analysis Approach}

Almost all of the lithologic information contained in the database compiled by Anderson and others (1996) reflects a dichotomous designation of sediment or basalt. Thus, the proportion of sediment encountered by a borehole can be expressed either as a cumulative thickness or as a percentage over a designated depth interval. Although both measures were evaluated during exploratory data analysis, the use of sediment percentages introduces statistical bias where sediment constitutes all of a composite unit's thickness (most frequently, in locations where a composite unit is relatively thin or incompletely penetrated by boreholes) and skews the statistics of sediment abundance relative to basalt. Where practical, cumulative thicknesses as well as percentage of sediment were statistically analyzed; note that for model layers A, B, and C, each of which is $100-\mathrm{ft}$ thick, measures of sediment thickness and percentage are numerically equivalent.

Exploratory analysis involved the computation of basic statistics for each composite unit's sediment content, an evaluation of the effect of geographically clustered wells on the computed statistics, and an examination of the hypothesis of statistical stationarity (both in a geographic spatial sense and in a time-stratigraphic spatial sense). As one test of statistical stationarity, nonparametric hypothesis tests were used to evaluate the degree of similarity between sample medians. A Mann-Whitney test, equivalent to a Student's t-test for normally distributed populations, was used to compare pairs of sample means; the Kruskal-Wallis test (equivalent to a one-way analysis of variance for normally distributed populations) was used to compare differences among three or more sample medians. All hypothesis tests were evaluated at a 95 percent confidence level (where a $p$-value greater than 0.05 indicates no statistically significant difference among the samples).

Autocorrelation analysis focused on the computation of various spatial statistics to characterize the scale over which the thicknesses of composite units and interbeds persist. These statistical measures provided additional support for the hypothesis of stationarity and served as the basis for developing models of sediment thickness via kriging.

\section{Kriging Approach}

Kriging is a nearest-neighbor predictor that makes statistically "best" estimates at unsampled locations on the basis of available information in local neighborhoods. It differs from other linear prediction methods in its reliance on a model of spatial autocorrelation (inferred from the data) to assign weights to nearest data neighbors. Kriging estimates are optimal in the sense that their estimation error variances are minimized. In ordinary kriging, the error variance provides an estimate of prediction uncertainty based on the assumption that estimation errors are normally distributed. In this sense, ordinary kriging has been described as a "parametric" estimator (Isaaks and Srivastava, 1989). It is often unrealistic, however, to assume that estimation uncertainty is normally distributed or that the ordinary kriging estimate, the mean, is an appropriate estimator of central tendency at all kriged locations. To avoid this limitation, multiple indicator kriging (mIK) uses nonlinear (indicator) transforms of data around multiple thresholds to estimate the cumulative frequency distribution (CFD) within a local neighborhood. The local CFD is unconstrained by assumptions of normality, and provides a true measure of estimation uncertainty due to local data variability as well as a more appropriate estimate of central tendency, the median. The drawback is that autocorrelation statistics must be calculated and an autocorrelation model inferred at each threshold used to discretize the CFD, making $\mathrm{mIK}$ more time consuming to implement. However, the power, flexibility, and generality of $\mathrm{mIK}$ make it the superior kriging technique for modeling environmental data (Goovaerts, 1997). All kriging results were discretized and converted to industry-standard shapefile format on a quarter-mile grid corresponding to the cell centers of the USGS subregional flow model.

\section{Software Selection}

Data organization, query building, and data extraction were performed with Microsoft Access ${ }^{\mathrm{TM}}$ database software; Microsoft Excel ${ }^{\mathrm{TM}}$ was used for data manipulation, sorting, and indicator transformation. Basic statistical analyses were performed with Minitab ${ }^{\mathrm{TM}}$ and StatMost ${ }^{\mathrm{TM}}$ statistical software, and ArcMap ${ }^{\mathrm{TM}}$ Geographic Information System software was used for spatial data visualization and graphics generation. Variogram analysis was performed with the VARIOWINTM software package (Pannatier, 1996), and declustering analysis and multiple indicator kriging were performed with the Stanford Geostatistical Software Library ${ }^{\mathrm{TM}}$ (GSLIB) (Deutsch and Journel, 1998). Results of geostatistical modeling were imported as GSLIB grids into ArcMap and converted to shapefiles and raster grids for visualization and raster-based computations. 


\section{Geostatistical Analysis and Modeling}

The goal of geostatistical analysis was to understand the distribution of sediment in a stratigraphic, three-dimensional spatial context in order to make defensible decisions during geostatistical modeling. In particular, statistical similarity among geologic units was evaluated to determine whether the sedimentary data were statistically stationary and could be modeled with kriging.

\section{Exploratory Data Analysis}

The total thickness of sediment encountered in boreholes around the INL is summarized in figure 4. Most sediment-rich boreholes occur within or near the boundary of the putative sedimentary basin known as the Big Lost Trough (dashed polygon). Note the relative paucity of boreholes that penetrate composite units older than unit 6 . The data have been segregated into groups representing wells that fully penetrate each of the composite stratigraphic units listed in table 1. More than 95 percent of all wells that encounter at least $25 \mathrm{ft}$ of sediment in each composite unit lie within or on the margins of the Big Lost Trough and are generally within 10 to $15 \mathrm{mi}$ of the present-day location of the Big Lost River.

\section{General Considerations: Spatial Clustering and Partial Penetration}

In statistically characterizing a spatial data set, the effect of spatial clustering must be considered. Spatially clustered data provide information redundancy in densely sampled areas and can bias calculated statistics toward values that reflect the most densely sampled areas, particularly if redundant sampling occurs in areas where the measured attribute is valued unusually high or low. In such cases, the spatial data must be appropriately weighted (declustered) to minimize this bias. In this study, the impact of such information redundancy is negligible. As shown in figure 5, the sample statistics changed only slightly when appropriate declustering weights were assigned, because boreholes are not preferentially clustered in areas of unusually high or low sediment content. Similar results were obtained when examining subsets of the data, broken down either by composite unit or by model layer.

The analysis of clustered data can be critical, however, in evaluating such characteristics as spatial autocorrelation and statistical stationarity of a population. Comparisons between areas of clustered and nonclustered data can provide evidence of spatial stationarity and help identify small-scale autocorrelation behavior. Furthermore, kriging automatically accounts for information redundancy, thus eliminating the need for declustering corrections.
All subsequent analyses in this study were performed without declustering. In all cases in which raw and declustered data were compared, the effect of declustering was to diminish the apparent differences between the sample populations being compared; in this sense, the raw data provided a worst-case test for comparing statistical similarity among composite units.

Of far greater concern than clustered data was the effect of partial penetration. In a borehole which only partially penetrates a composite unit, the reported thickness of that unit or its sediment content is censored (quantified by an inequality, such as "greater than" an apparent thickness; Helsel and Hirsch, 2002). Bias arises when the censored information is compared with data from other boreholes that fully penetrate the same unit. Unlike other types of environmental information (where censoring occurs consistently in only one sense, such as when imposed by a detection limit, for example), borehole partial penetration bias is bi-directional and random. That is, if a composite unit happens to be sediment rich, then the proportion of sediment sampled by a partially penetrating borehole would represent an upper limit; alternatively, if the borehole penetrates a sediment-poor zone, the measurement would be biased low. In the case of the INL data, partial penetration should not introduce bias because such censoring is expected to be bi-directional and randomly expressed.

Wherever possible, only those sediment thicknesses defined by fully penetrating boreholes were considered. Fortunately, sediment typically represents less than 15 percent of a borehole's length, so that partial penetration bias is infrequent and has negligible effect. Except in the most infrequently sampled composite units, the attendant reduction in sample size is about 5 percent or less. It was necessary to use all available sedimentary thickness data because of limited sample size only in the aggregated composite unit 8 to 14 , where just five deep boreholes fully penetrate.

Only the ground-water model layers (A, B, and C [fig. 3]), corresponding to the uppermost $300 \mathrm{ft}$ of the saturated zone, were considered in this study. An insufficient number of fully penetrating boreholes were available in layers $\mathrm{D}$ and deeper to justify a statistical analysis. For comparative purposes, the unsaturated zone (layer $\mathrm{U}$ ) was also statistically analyzed but not kriged.

\section{Sediment Abundance by Composite Unit}

The statistical variability of sediment thickness in boreholes that fully penetrate each composite unit is shown in figure 6. The exception is the aggregate package, composite units 8 to 14 , whose oldest units are fully penetrated by only five boreholes and which was analyzed without an adjustment for partial penetration. 

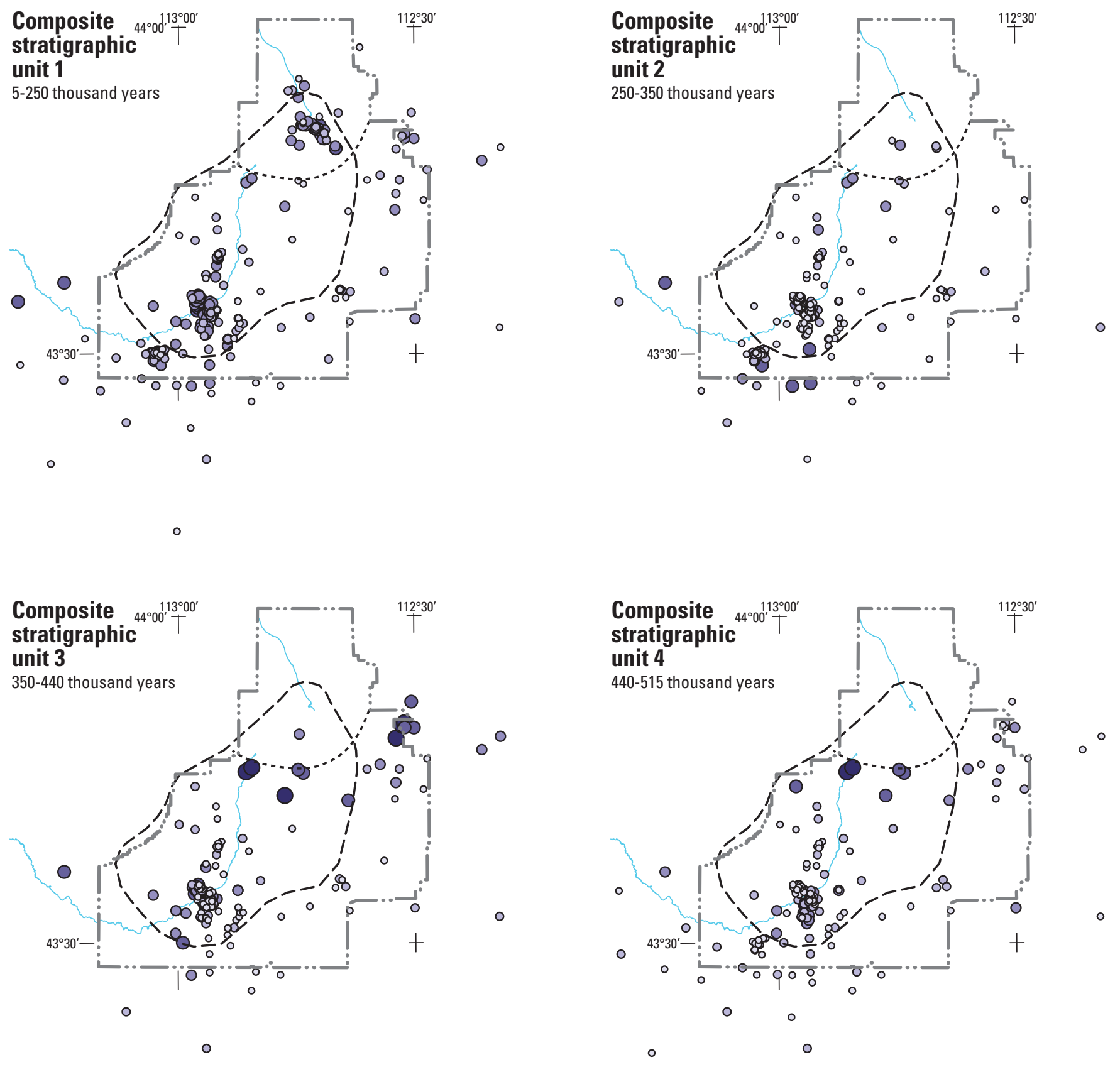

\section{EXPLANATION}
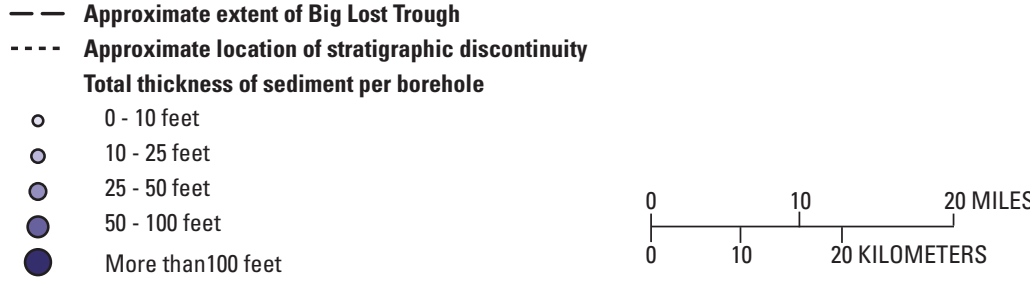

Base from U.S. Geological Survey digital data, 1:24,000 and 1:100,000 Albers Equal-Area Conic projection Standard parallels $42^{\circ} 50^{\prime} \mathrm{N}$ and $44^{\circ} 10^{\prime} \mathrm{N}$, central meridian $113^{\circ} 00^{\prime} \mathrm{W}$

Datum is North American Datum of 1927

Figure 4. Geographic distribution of sediment-rich and sediment-poor boreholes that fully penetrate composite stratigraphic units 1 through 7 and 8 through 14, as defined by Anderson and Liszewski (1997). 


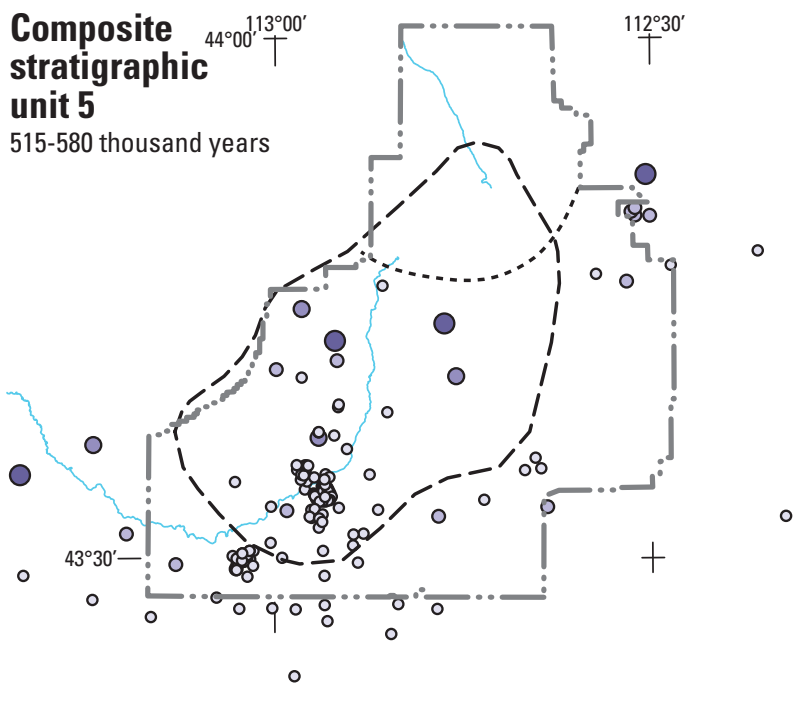

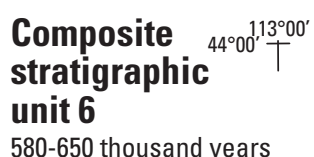

$580-650$ thousand years

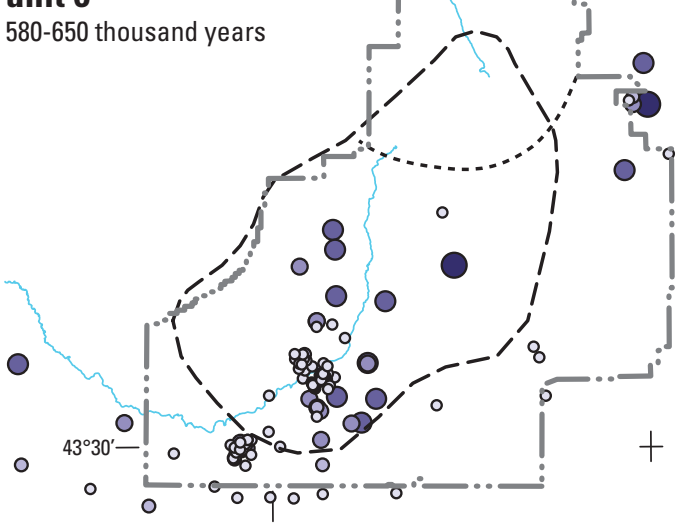

0
0

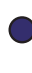

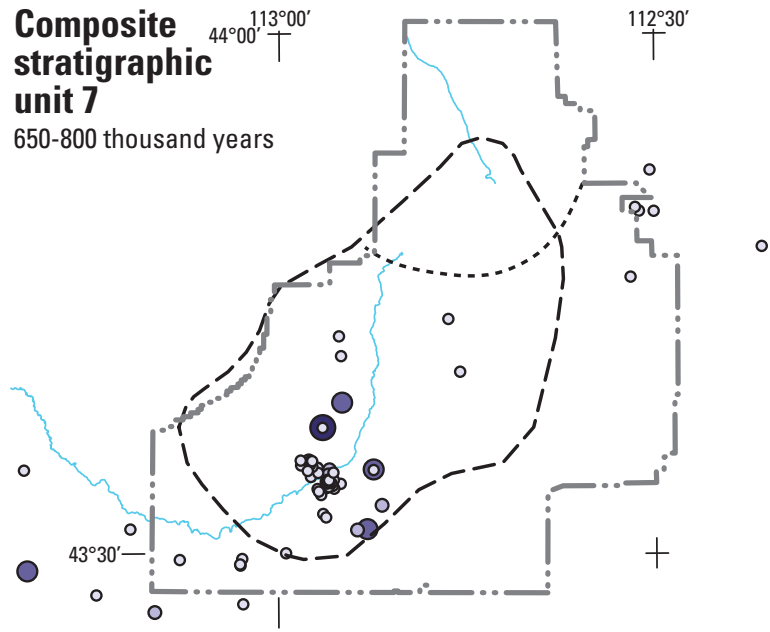

$\circ$

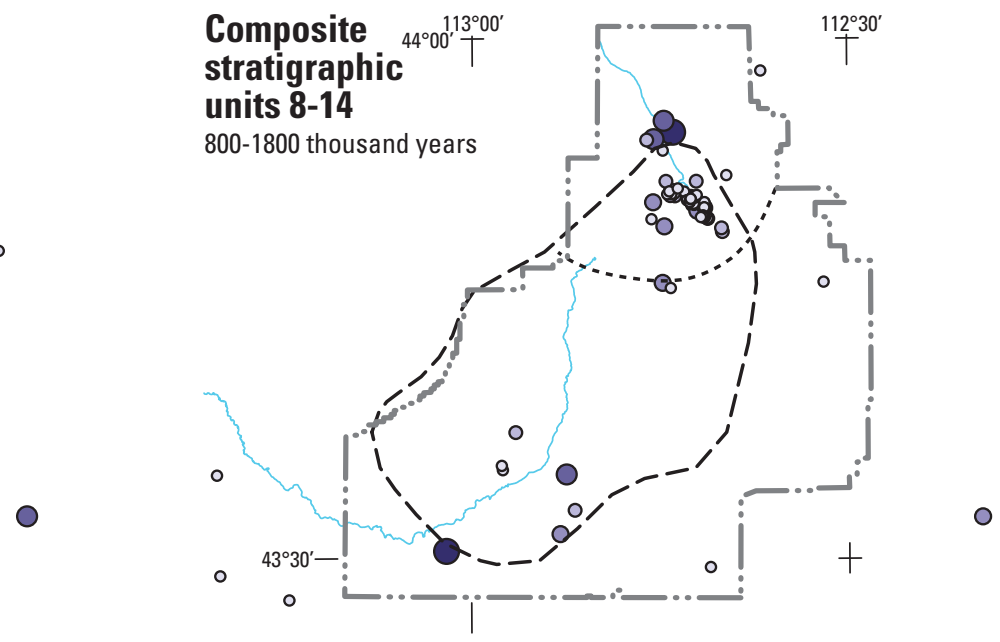

$\circ$

\section{EXPLANATION}

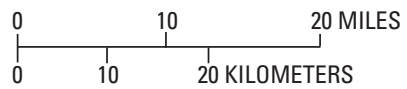

- Approximate extent of Big Lost Trough

Approximate location of stratigraphic discontinuity

Total thickness of sediment per borehole

0 - 10 feet

$10-25$ feet

25 - 50 feet

50 - 100 feet

More than 100 feet
Base from U.S. Geological Survey digital data, 1:24,000 and 1:100,000 Albers Equal-Area Conic projection Standard parallels $42^{\circ} 50^{\prime} \mathrm{N}$ and $44^{\circ} 10^{\prime} \mathrm{N}$, central meridian $113^{\circ} 00^{\prime} \mathrm{W}$

Datum is North American Datum of 1927

Figure 4.-Continued. 


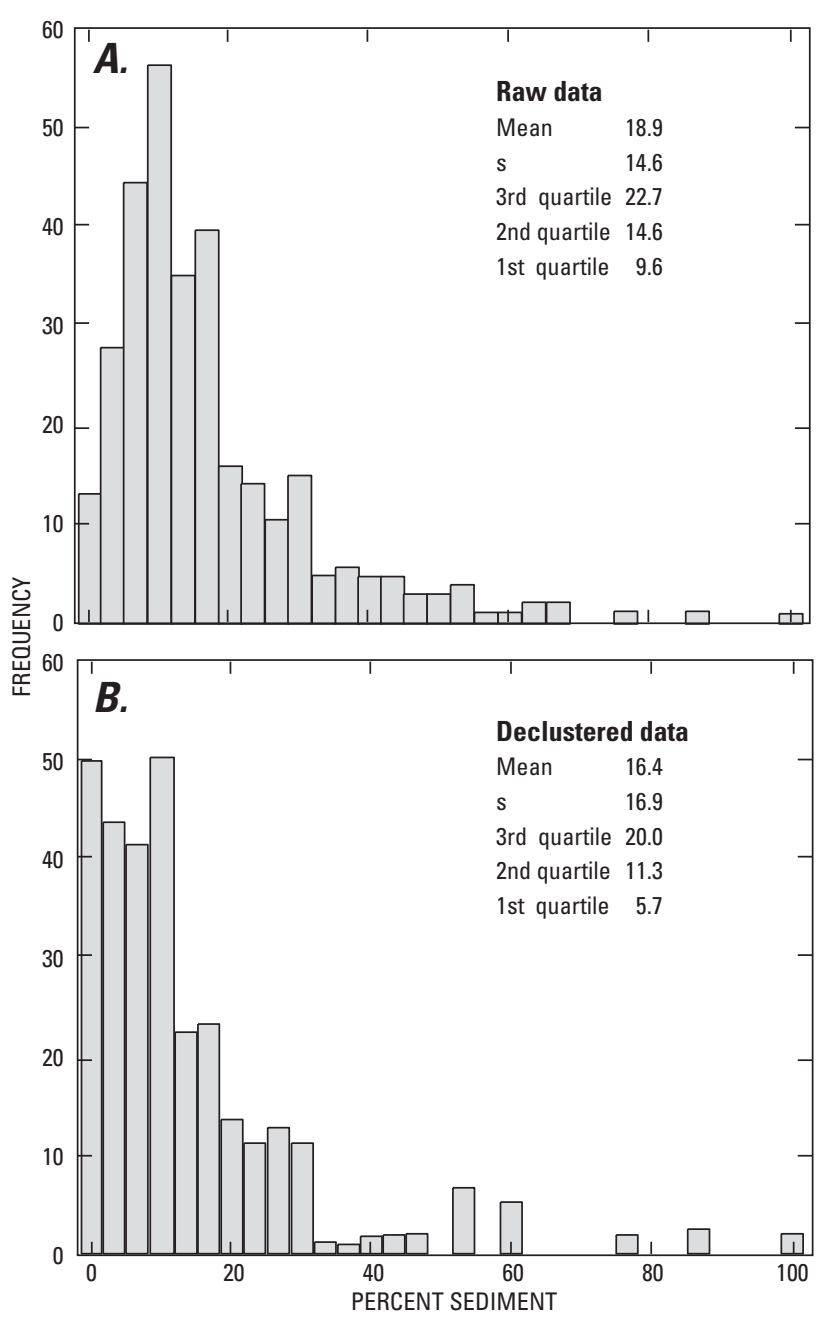

Figure 5. Comparative distributions of sediment abundances showing the effect of spatial clustering on summary statistics. $(A)$ sediment abundance data derived from spatially clustered boreholes may bias the statistics that summarize the central tendency and (or) spread of a distribution; $(B)$ effect of redundant information is reduced by assigning appropriate declustering weights, leading to more representative summary statistics. Sample standard deviation is denoted by $\mathrm{s}$.
The box plots in figure 6 clearly show that sediment comprises a significantly larger proportion of the thickness of composite unit 1 than of any of the older units. A similar pattern holds when considering sediment as a percentage of composite unit thickness (fig. 7). The distribution of sediment in composite unit 1 is strikingly different from that in all other composite units. ${ }^{6}$ Of the older composite units, some of whose sediment thickness distributions are statistically similar, the distribution in composite unit 5 is the most skewed and has the lowest median sediment content. However, it also represents the shortest accumulation period of any of the seven youngest composite units ( $65 \mathrm{Ka}$, table 1$)$, raising the possibility that its anomalous character reflects an under-sampled stratigraphic interval.

To test this hypothesis and to further evaluate the case for statistical similarity over time, different groupings of composite units were combined into longer time spans of similar duration. Selected results for grouped units are shown in figure 8 , for sediment percentages and figure 9 , for sediment thicknesses. Nonparametric tests of similarity were conducted to identify whether median sediment abundances are more similar than not; statistical comparisons for various groupings that have similar distributions of sediment percentage and of sediment thickness, respectively, are summarized in tables 2 and $\underline{3}$. Overall, the results indicate that the relative sediment contents of composite units older than unit 1 are statistically more similar than they are different. An important caveat is that some of the sediment data representing composite units 8 through 14 originates from partially penetrating boreholes and therefore may be biased. The inference of statistical similarity between these and younger units, therefore, remains tentative.

These results underscore the difficulty in assessing statistical similarity in geologic units over time and space. Substantial variation in sediment thickness or in percentage of sediment in total thickness among units arises because of limited geographic representation or because the geologic time intervals being considered are not representative of long-term average sediment accumulation rates. The results of tables 2 and $\underline{3}$ indicate that time intervals of about 100-200 Ka or larger are required if meaningful comparisons are to be made in this sense.

\footnotetext{
${ }^{6}$ Tests of similarity with other composite unit medians returned a MannWhitney $p$-value of 0.00 in all instances.
} 


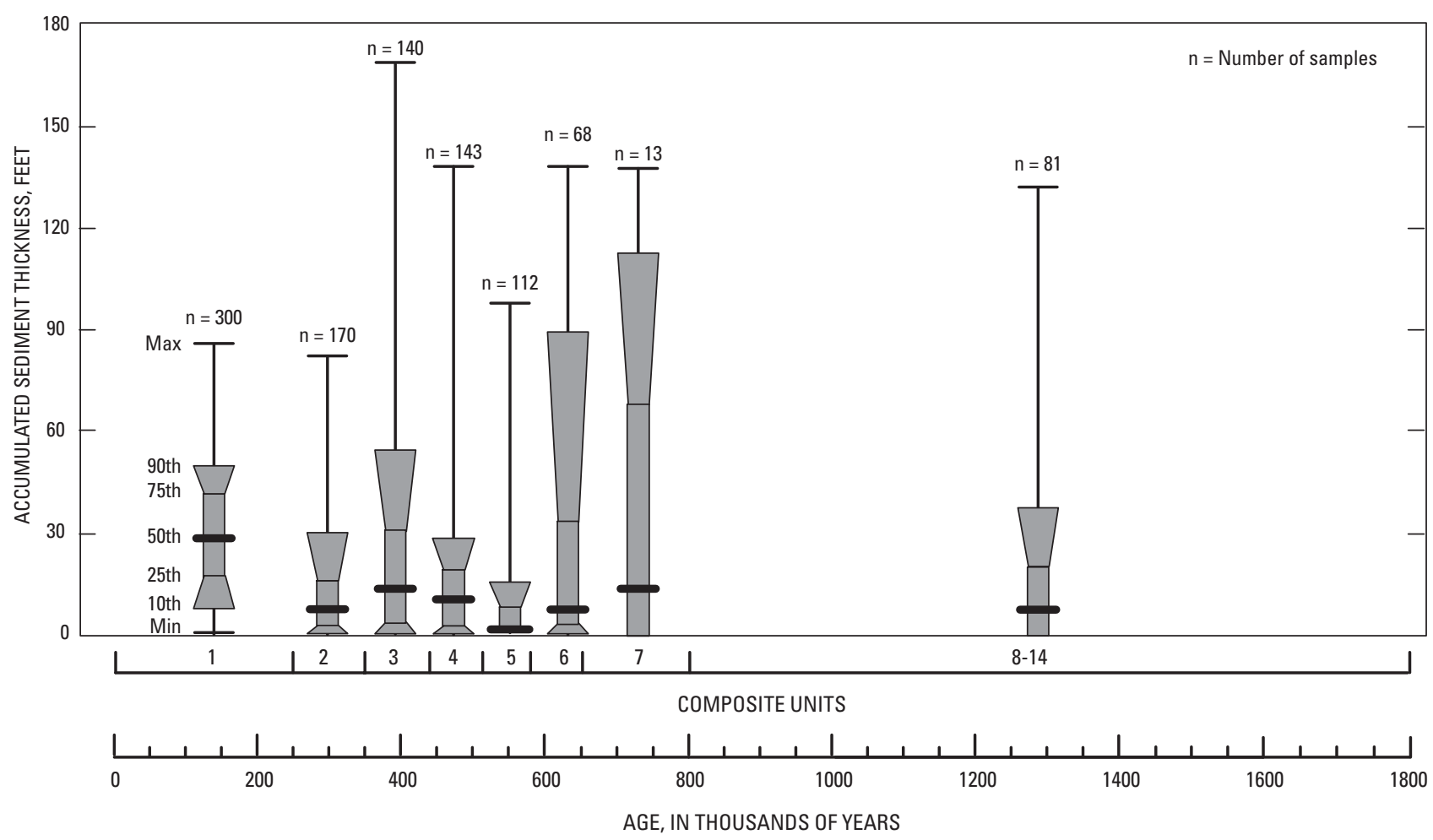

Figure 6. Distribution of thickness of total accumulated sediment in boreholes that fully penetrate individual composite units 1 through 7 and in boreholes that penetrate the oldest units 8 to 14 combined. Approximate time spans are from table 1.

Other than the relatively high sediment content noted in composite unit 1 , sediment distributions appear similar when examined over sufficiently long time spans to average out short-term differences in sediment accumulation rates and sampling-induced noise. The data reveal no apparent trend over time in either accumulated sediment thickness or in its proportion relative to basalt. Composite unit 1's high sediment content may reflect the period of relative volcanic quiescence over the past $200 \mathrm{Ka}$ (Anderson and others, 1997; Champion and others, 2002), the interval during which most of composite unit 1 accumulated. If so, then sedimentation rates during this period may not have necessarily increased relative to earlier periods during which basalt accumulation rates were higher.

\section{Sediment Abundance by Model Layer}

From the preceding analysis, it appears that except for the time span represented by composite unit 1 , sediment abundance relative to basalt has not changed substantially over time. For the purposes of spatial modeling, such a conclusion is vital to any approach that aggregates borehole data into still larger groupings (such as ground-water model layers) that crosscut aquifer stratigraphy (fig. 3).

Locations of fully penetrating boreholes in each of the uppermost three ground-water model layers that represent the saturated zone are shown in figure 10. All subsequent statistical analyses were carried out on the basis of sediment percentages within these three, 100-ft thick layers (where percentages are numerically equivalent to thickness in feet). 


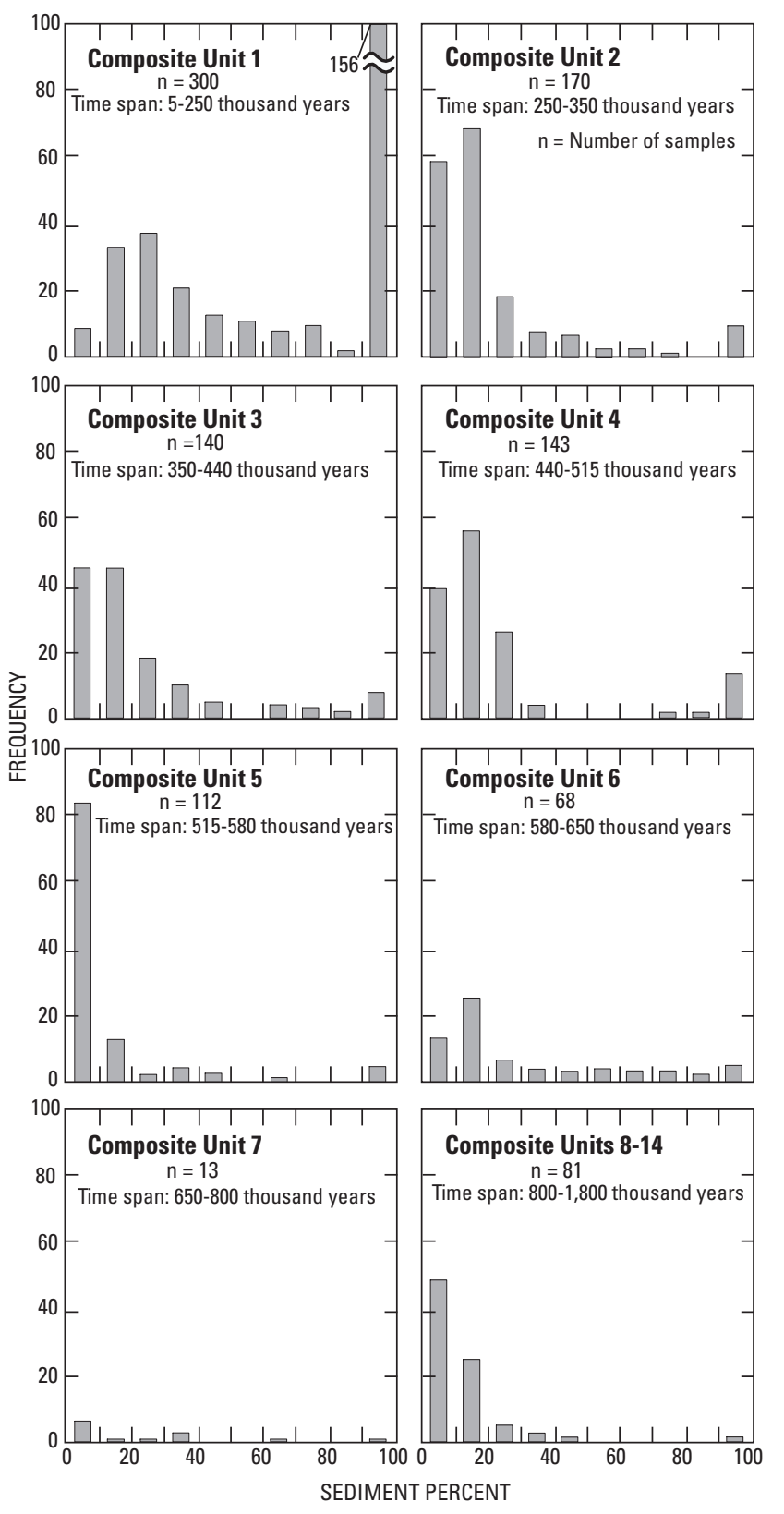

Figure 7. Sediment abundance in each of composite units 1 through 7 and in combined unit 8 to 14 , as a percentage of composite unit thickness.
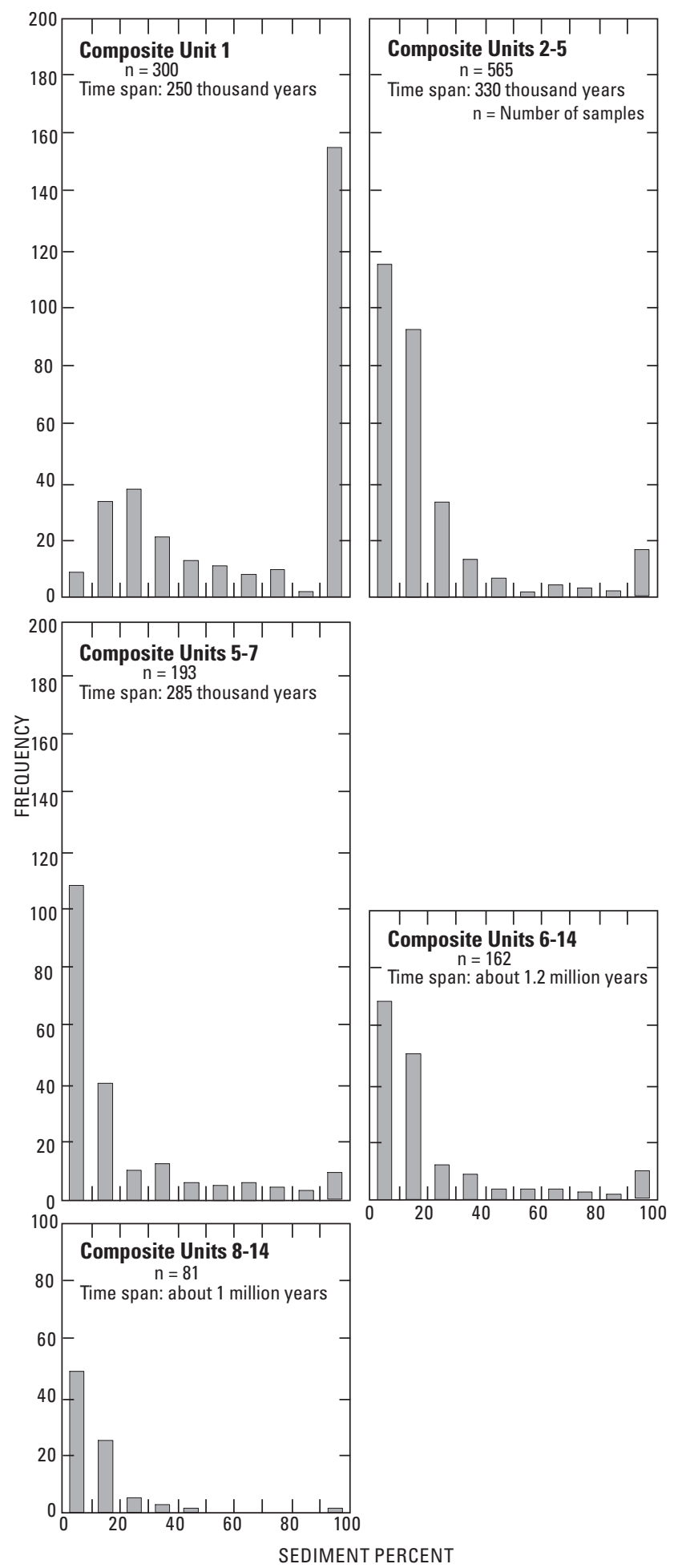

Figure 8. Distributions of sediment percentage in various groupings of composite units showing evidence of statistical similarity among the youngest (other than composite unit 1) and the oldest. 
Table 2. Results of nonparametric tests of similarity of median sediment content between various groupings of younger and older composite units, where sediment content is expressed in percent.

[Abbreviations: Ka, thousands of years; M-W, Mann-Whitney test of similarity; $p$-value, probability value; vs., versus]

\begin{tabular}{ccr}
\hline $\begin{array}{c}\text { Groupings of } \\
\text { composite units }\end{array}$ & $\begin{array}{c}\text { Time spans } \\
\text { compared } \\
\text { (Ka) }\end{array}$ & $\begin{array}{c}\text { Test of similarity } \\
\boldsymbol{p} \text {-value }\end{array}$ \\
\hline $3-5$ vs. $6-14$ & 230 vs. 2,020 & $0.504(\mathrm{M}-\mathrm{W})$ \\
$2-5$ vs. $6-14$ & 330 vs. 2,020 & $.847(\mathrm{M}-\mathrm{W})$ \\
$5-7$ vs. $8-14$ & 285 vs. 1,800 & $1.000(\mathrm{M}-\mathrm{W})$ \\
$3-7$ vs. $8-14$ & 450 vs. 1,800 & $.300(\mathrm{M}-\mathrm{W})$ \\
\hline
\end{tabular}

Table 3. Results of nonparametric tests of similarity of median sediment content between groups of younger and older composite units, where sediment content is expressed as sediment thickness.

[Abbreviations: Ka, thousands of years; M-W, Mann-Whitney test of similarity; K-W, Kruskal-Wallis test of similarity; $p$-value, probability value; vs., versus]

\begin{tabular}{rcr}
\hline $\begin{array}{c}\text { Groupings of } \\
\text { composite units }\end{array}$ & $\begin{array}{c}\text { Time spans } \\
\text { compared } \\
\text { (Ka) }\end{array}$ & $\begin{array}{c}\text { Test of similarity } \\
\boldsymbol{p} \text {-value }\end{array}$ \\
\hline $2-7$ vs. $8-14$ & 550 vs. 1,800 & $0.792(\mathrm{M}-\mathrm{W})$ \\
$2-5$ vs. $6-7$ vs. $8-14$ & 330 vs. 220 vs. 1,800 & $.221(\mathrm{~K}-\mathrm{W})$ \\
2 vs. $3-7$ vs. $8-14$ & 100 vs. 350 vs. 1,800 & $.898(\mathrm{~K}-\mathrm{W})$ \\
\hline
\end{tabular}

Similarities and differences among the sediment contents of these layers, as well as in the layer that represents the unsaturated zone, are summarized in figure 11. At the 95-percent confidence level, nonparametric tests of similarity among pairs of model layers show that sediment distributions in layers $\mathrm{A}, \mathrm{B}$, and $\mathrm{C}$ range from marginally distinguishable to statistically indistinguishable. ${ }^{7}$ Considering this together with the similarity of median abundances of sediment among composite units, the results indicate that the amount of sediment in the uppermost $300 \mathrm{ft}$ of the aquifer is statistically stationary in the vertical sense.

To evaluate statistical stationarity in the geographic sense, nonparametric tests of similarity were applied to sediment data from three different geographic groupings of boreholes

\footnotetext{
${ }^{7}$ A Kruskal-Wallis nonparametric test of similarity among layers A, B, and $\mathrm{C}$ returned a $p$-value of 0.032 indicating that their sediment distributions are marginally different; layers $\mathrm{A}$ and $\mathrm{C}$ are the most different (Mann-Whitney $p$-value $=0.01)$, whereas layers A and B are statistically similar, as are B and $\mathrm{C}$ (Mann-Whitney $p$-values $=0.28$ and 0.11 , respectively).
}

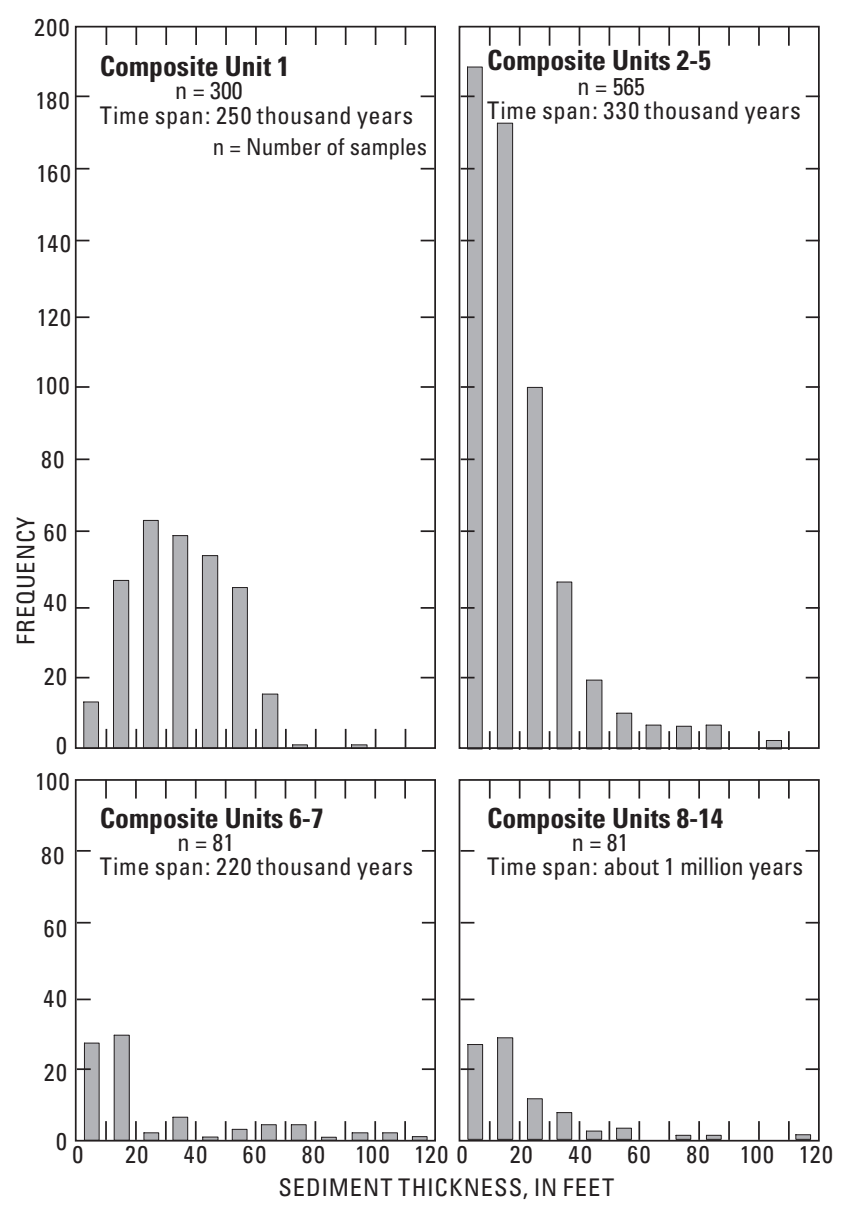

Figure 9. Distributions of total sediment thickness among various groupings of composite units. For rocks older than unit 1 , the similarity in histogram shape among various age-range groupings and the results of nonparametric tests of similarity (table 3 ) indicate that the amount of sediment relative to basalt has remained fairly similar over time.

in each of the model layers A, B, and C (fig. 10): (1) sediment data from nonclustered boreholes south of the stratigraphic discontinuity, (2) data from clustered boreholes south of the discontinuity, and (3) data from clustered boreholes north of the discontinuity. Histograms of these data groupings, together with the associated $p$-values for tests of similarity among the geographic groupings within each layer are presented in figure 12. Note that insufficient data precluded a comparison for the southern clustered area in layer C. Within each layer, the three data groupings are statistically indistinguishable at the 95-percent confidence level, indicating that median sediment abundance does not vary in a geographic sense. 

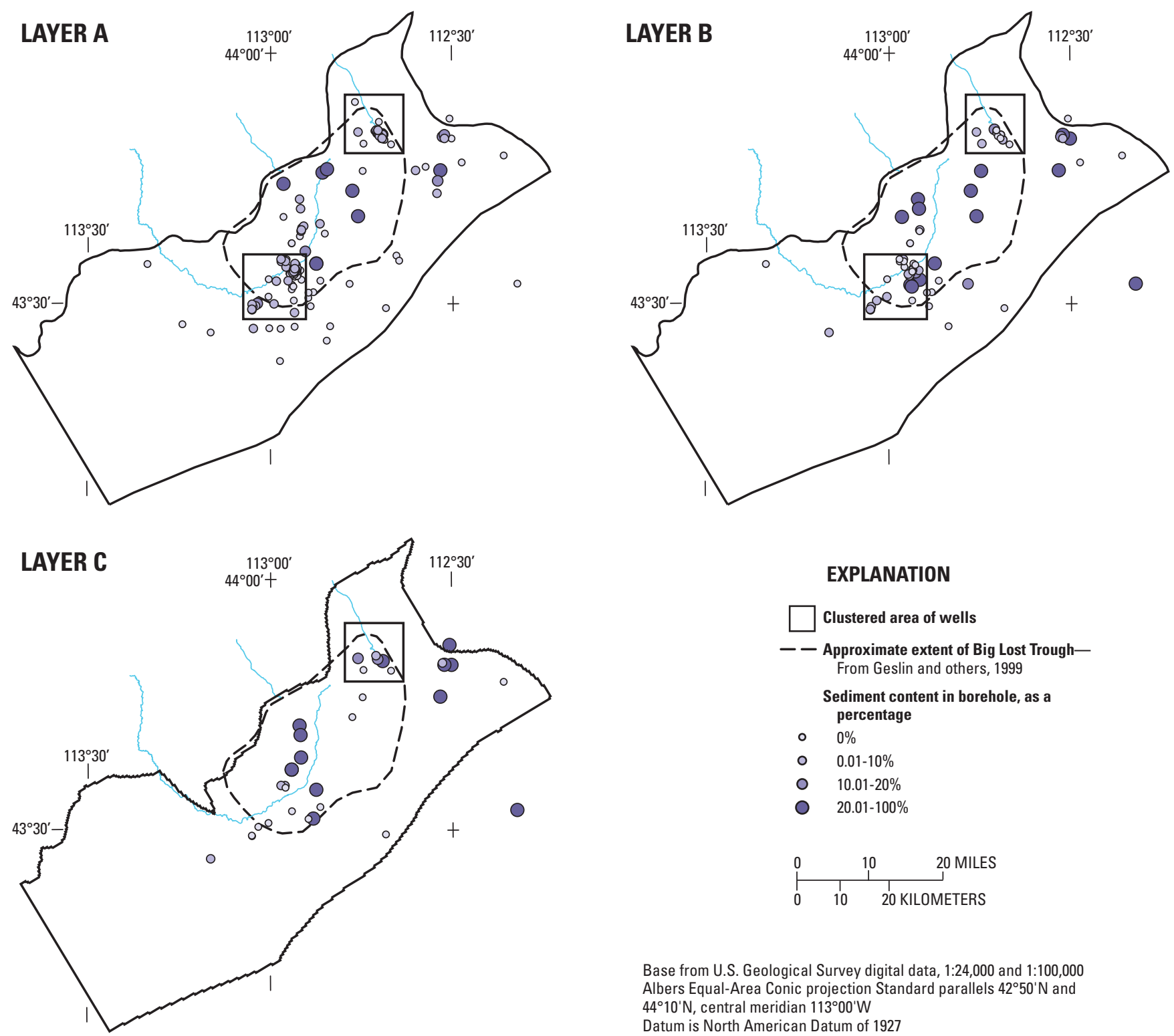

EXPLANATION
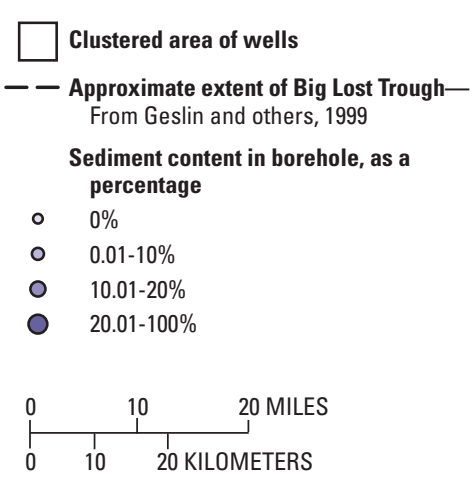

Base from U.S. Geological Survey digital data, 1:24,000 and 1:100,000 Albers Equal-Area Conic projection Standard parallels $42^{\circ} 50^{\prime} \mathrm{N}$ and $44^{\circ} 10^{\prime} \mathrm{N}$, central meridian $113^{\circ} 00^{\prime} \mathrm{W}$

Datum is North American Datum of 1927

Figure 10. Availability of boreholes that fully penetrate each model layer and that were used to model the two-dimensional spatial abundance of sediment in each model layer. Boxes differentiate north- and south-clustered areas of wells used to evaluate spatial stationarity (see fig. 12).

\section{Conclusions Derived from Exploratory Analysis}

Sediment abundances within the composite units appear to be statistically similar over time when sufficiently long time spans (groupings of composite units) are compared. When the data are grouped by model layer, or by geographic area within model layers, median sediment abundances in the uppermost $300 \mathrm{ft}$ of the saturated zone appear to be statistically similar, further corroborating the inferences made on the basis of the composite unit analysis. Dissimilarity is apparent only in the very youngest composite unit (representing most of the shallowest part of the unsaturated zone) and makes the unsaturated zone, as a whole, statistically unique in terms of its sediment content. On this basis, it is concluded that the median sediment contents of rocks below the water table are statistically similar when grouped by either composite unit, by model layer, or by geographic area within a model layer, indicating that the sediment content of the aquifer may be statistically stationary in a three-dimensional spatial sense. 


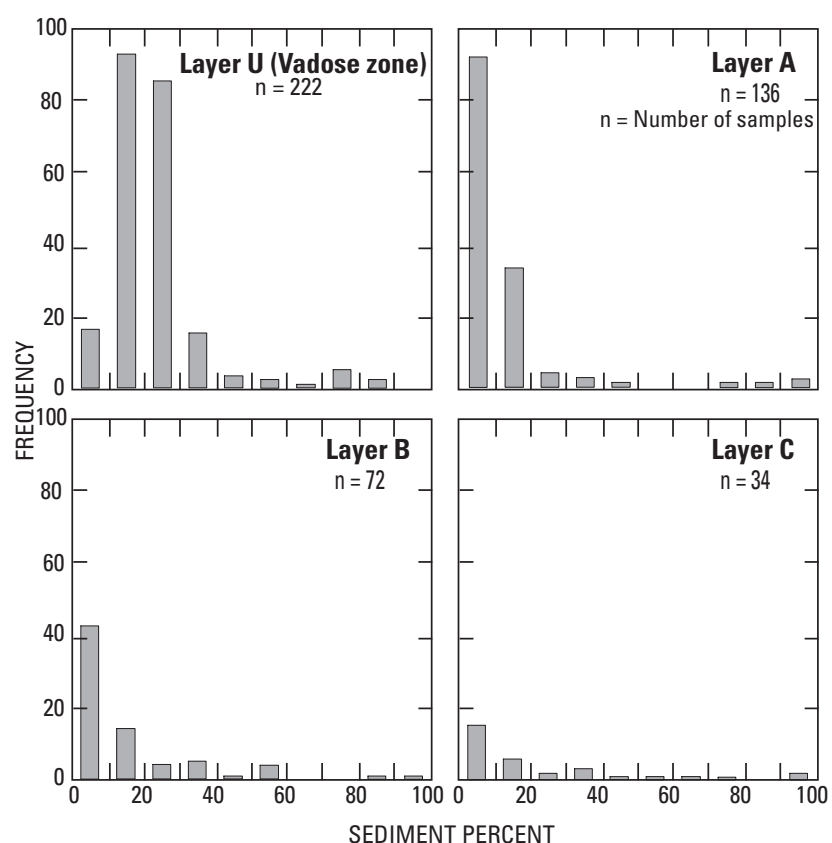

Figure 11. Distributions of sediment percentages in boreholes that fully penetrate layers $A, B$, and C, showing similar distributions, and in the unsaturated zone (layer $\mathrm{U}$ ), which has a substantially different distribution because of the influence of composite unit 1 (see figures 6 and 7 ).

\section{Autocorrelation Analysis}

The analysis of autocorrelation behavior involves the computation of sample statistics that characterize the degree of similarity of data values in space (information redundancy), followed by the inference of a model of autocorrelation structure from those sample statistics. In a nonrandom process such as sediment accumulation, the degree of similarity is greatest when pairs of closely spaced measurements are compared; measurements taken farther apart tend to be less similar. Autocorrelation statistics such as the autocovariance or the semivariogram provide a quantitative measure of the rate at which this similarity decreases with separation distance. These statistical measures, collectively referred to as variogram statistics, are the foundation on which all twopoint geostatistical inference and modeling is based. They are represented by plots of a variance-like statistical quantity (for example, the semivariogram) as a function of separation distance. The geometric structure of such plots is described in terms of a model of spatial autocorrelation, a curvilinear function characterized by a nugget (uncorrelated variance at zero separation), a range (separation distance over which autocorrelation disappears), and a sill (uncorrelated sample variance among pairs of data values separated by distances greater than the range). The presence of a horizontal sill that corresponds to the sample variance is the strongest indication that the data are second-order stationary, as required for most kriging applications.

\section{Variography of Composite Units}

The results of autocorrelation analysis of sediment thickness within individual composite units are summarized in figure 13, for composite units 1 through 6 (the spatial density of boreholes within composite units 7 and 8-14 was too low to warrant a similar analysis). A relative variogram estimator (the inverted correlogram) was used to simplify intercomparison of autocorrelation structure among the composite units. Variogram statistics were calculated at two different spatial lags to better assess the structure of the variogram's transition zone and the magnitude of its nugget. Because of its small sample size $(n=68)$, the variogram for composite unit 6 is poorly defined, but it appears to fit the same autocorrelation model as other composite units. Similar autocorrelation structure is evident for all composite units shown, with a welldefined sill and clear transition zone, a relative nugget of about 40 percent, and similar autocorrelation ranges.

It is noteworthy that all composite units share a similar autocorrelation structural model. Their well-defined sills, together with the uniformity of their autocorrelation ranges (from 20,000 to 25,000 ft) corroborates the inference of statistical stationarity across time-stratigraphic boundaries. In particular, the similarity of composite unit 1's autocorrelation structure to other composite units substantiates the conjecture that its relative sediment content differs not because of fundamental changes in sedimentation rate or spatial patterns, but because of a decrease in lava accumulation rate.

The statistical similarity of medians among different geographic groupings of boreholes within each model layer (fig. 12) and the similarity in autocorrelation structure among composite units (fig. 13) indicate that sediment abundance is a geographically stationary population. Although this conclusion must remain tentative in view of the paucity of spatial information at greater borehole depths and in certain parts of the study area, a preponderance of evidence supports the hypothesis of statistical stationarity within at least the uppermost $300 \mathrm{ft}$ of the ground-water flow model domain. 


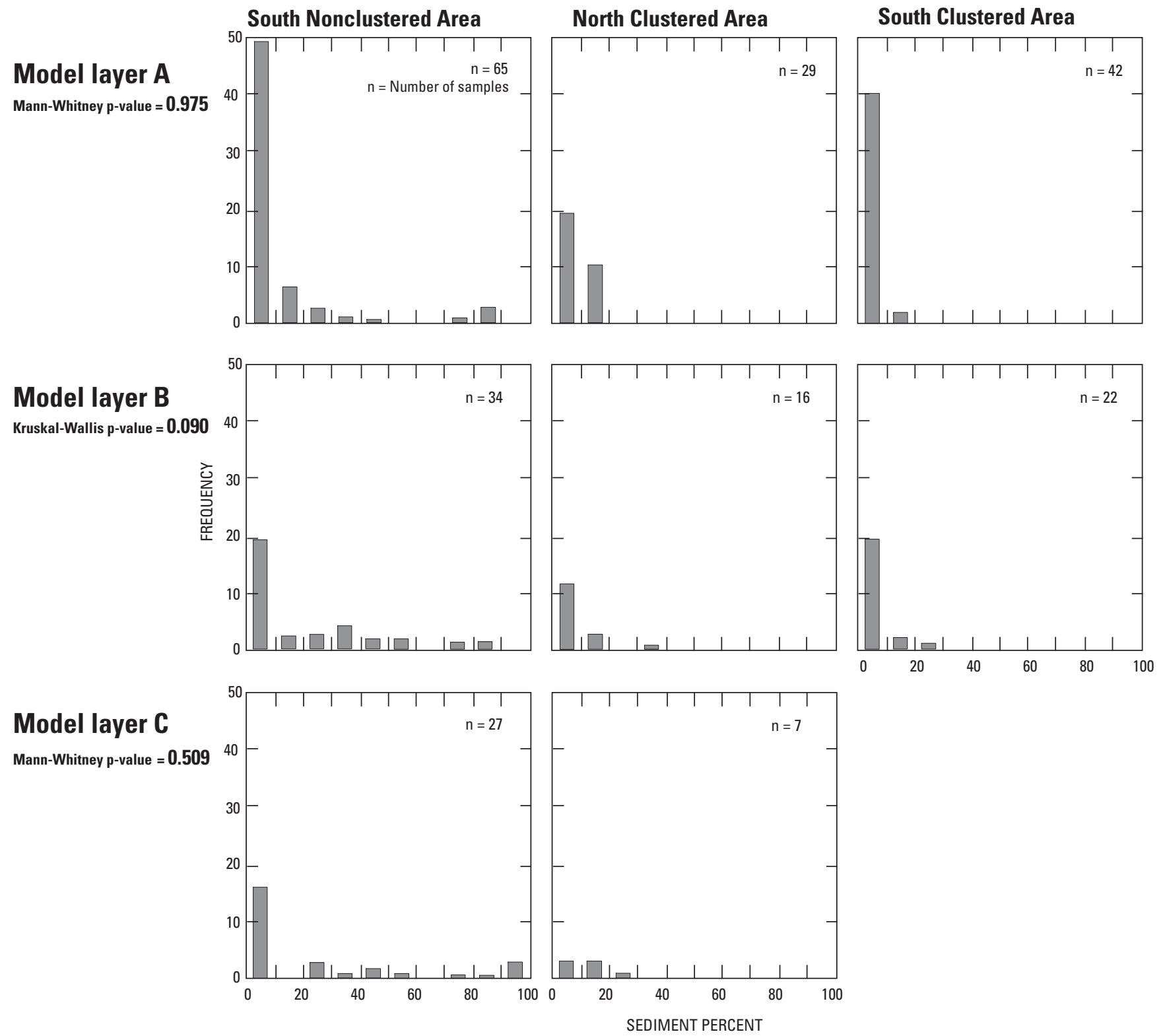

Figure 12. Distributions of sediment percentage from fully penetrating wells in model layers A, B, and $C$ in different areas north and south of the stratigraphic discontinuity and among clustered and nonclustered areas shown in figure 10. Probability values ( $p$-values) refer to nonparametric tests of similarity among geographic groupings of wells. 

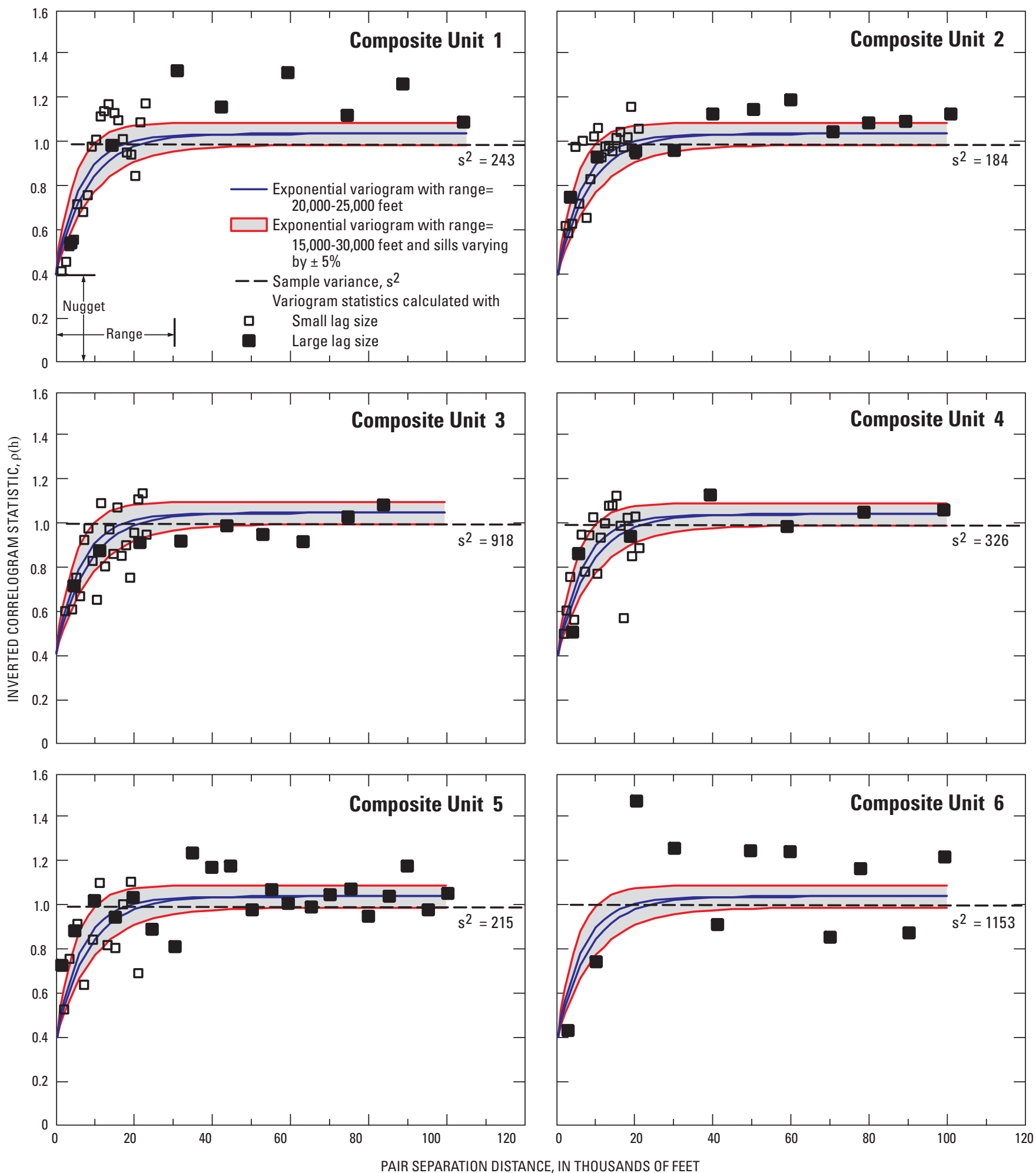

Figure 13. Relative variograms of sediment thickness within composite units 1 through 6 , based on the inverted correlogram statistic. Variograms are plotted at two lag sizes to elucidate the variogram range and nugget. All fitted models have a relative nugget of 40 percent of the sample variance. 


\section{Indicator Variography of Model Layers}

For the purposes of $\mathrm{mIK}$, the cumulative frequency distribution (CFD) of sediment percentage is discretized and approximated by a series of indicator transformations of the original data. By way of example, the borehole data for layer A (expressed as sediment percentages) was transformed around twelve indicator thresholds at 1 percent increments from 1 to 12 percent sediment (few boreholes in this layer have higher sediment contents, making transformation at higher thresholds impractical). At each threshold, the following indicator transformation was applied: for example, at a 7 percent sediment threshold, each data value was transformed using the following relationship:

$$
\begin{aligned}
& I_{i}=1 \text { if } Z_{i} \leq 7 \text { percent } \\
& I_{i}=0 \text { if } Z_{i}>7 \text { percent, }
\end{aligned}
$$

where

$Z_{i}$ are the original data values (sediment percentages), and the $I_{i}$ are their indicator-transformed values.

The average of the transformed values provides an estimate of the global CFD's $p$-quantile (probability value) at that threshold:

$$
p=(1 / n) \Sigma I_{i}
$$

The thresholds at which the indicator transformations were carried out for each layer and the resulting indicatorderived probabilities are shown in figure 14. The dashed lines portray the global CFDs that would be plotted using the untransformed data. In effect, multiple indicator transformation allows a distribution's shape to be estimated from a series of nonlinear transformations of the original data. A different set of thresholds was applied to each model layer because the shapes of their global CFDs and the amount of data in the upper tails of their distributions differed greatly.

Multiple indicator kriging uses the autocorrelation structure of the indicator variograms at each threshold to calculate optimal kriging weights, from which the local CFD's conditional probabilities are estimated at each of several thresholds. The principal strength of $\mathrm{mIK}$ is that different spatial autocorrelation structure can be accommodated across the range of the data being kriged. Figure 15 shows examples of layer A's indicator variograms and how the autocorrelation
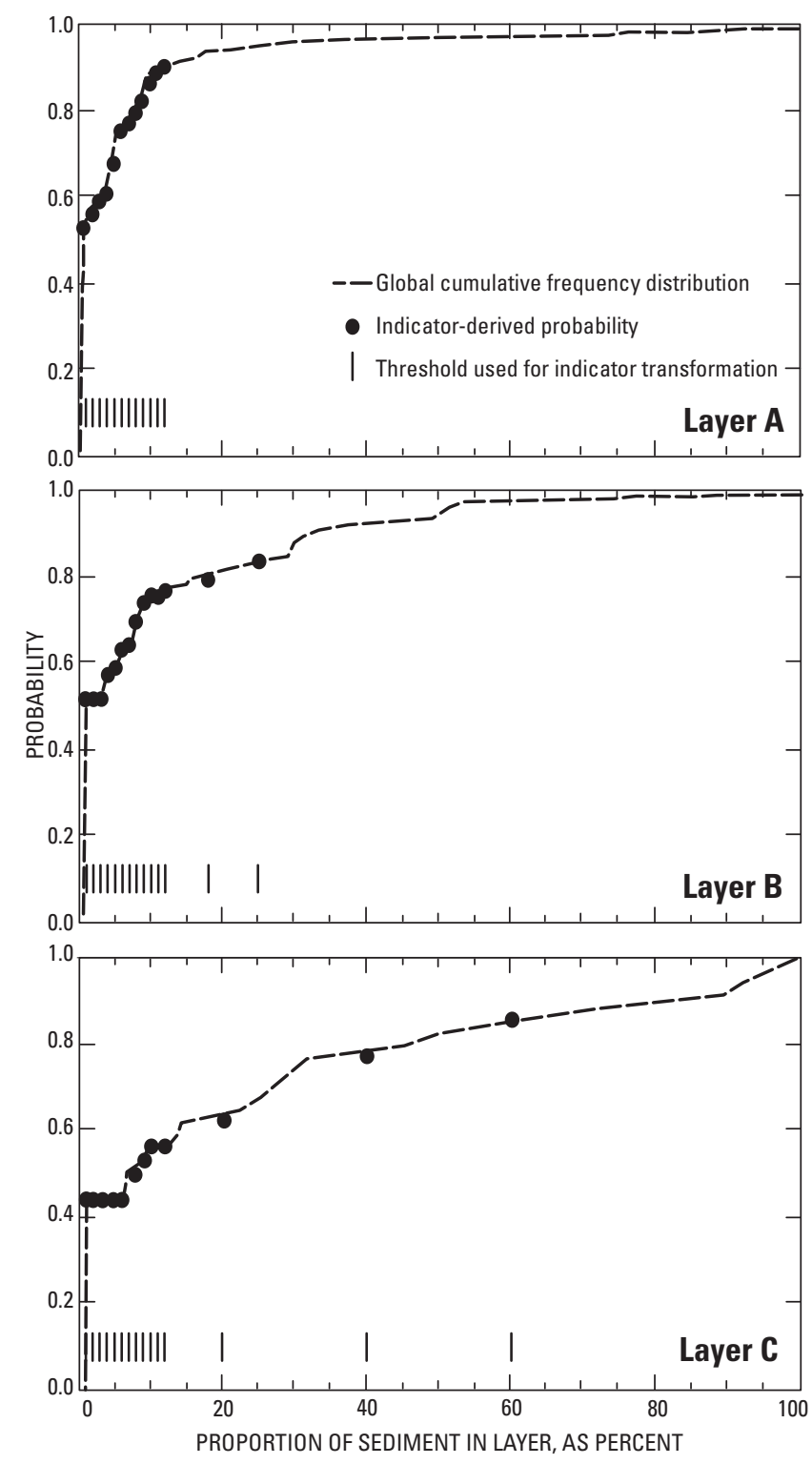

Figure 14. Cumulative frequency distributions (CFDs) of sediment percentage in boreholes that fully penetrate layers $A, B$, and $C$ showing CFD probabilities calculated from equation 1.

structure changes from one threshold to the next, reflecting the degree to which high and low values are spatially autocorrelated. All indicator variograms display clearly defined sills, providing further support for the hypothesis that the sediment abundance data reflect a globally stationary variable (Isaaks and Srivastava, 1989). 

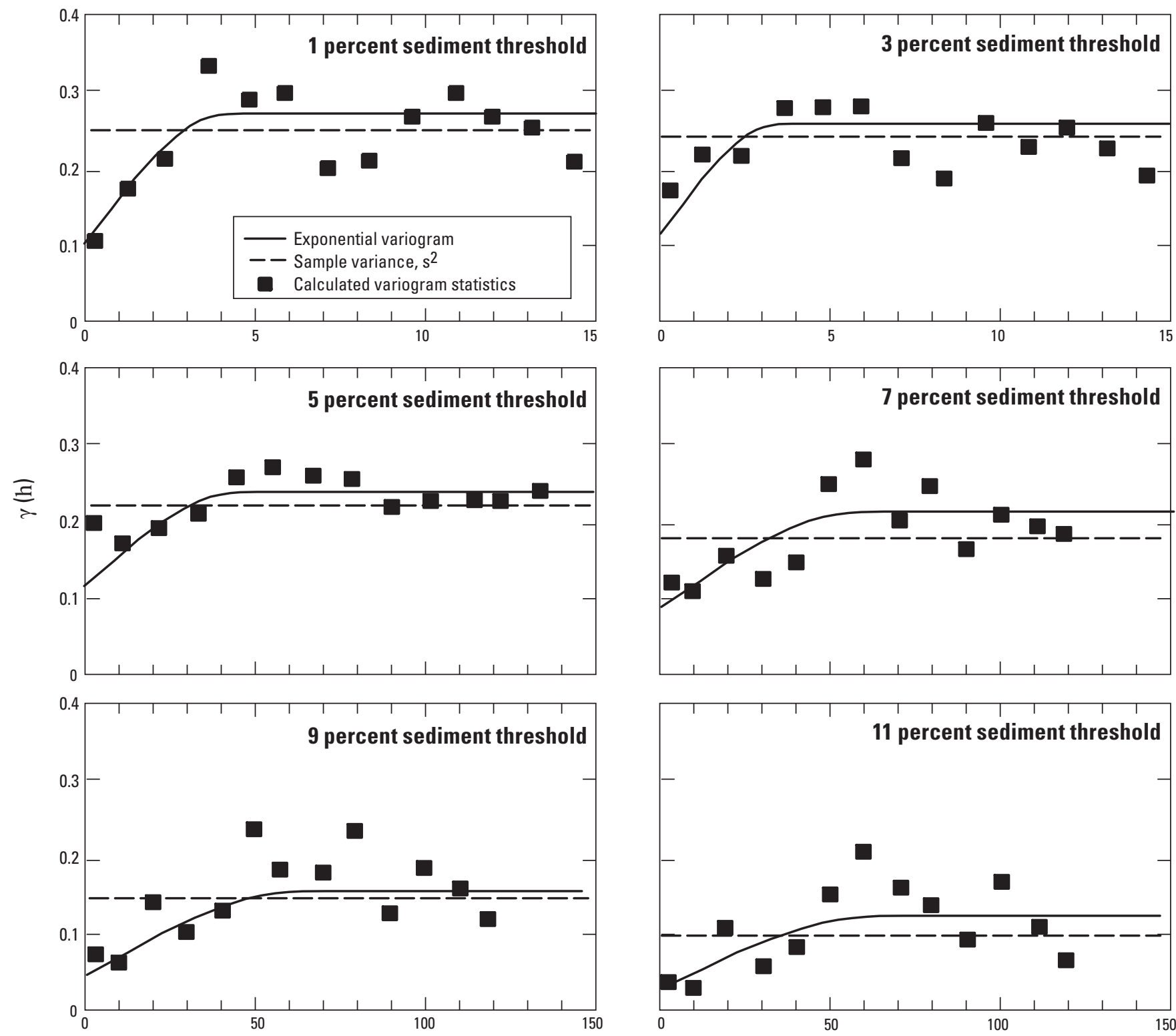

PAIR SEPARATION DISTANCE, IN THOUSANDS OF FEET

Figure 15. Examples of multiple indicator semivariograms at selected thresholds for layer A, showing the nature of the autocorrelation structure and the progressive change in nuggets, sills, and ranges as thresholds increase. Note that the horizontal axes for the 1- and 3-percent thresholds are 10 times smaller than for larger thresholds. 
Indicator variogram model parameters for the 12 thresholds subsequently used to make mIK estimates for layer A are summarized in figure 16. Because the choice of CFD thresholds is arbitrary, care must be taken to ensure that the variogram model parameters inferred at one threshold are compatible with parameter values inferred at neighboring thresholds (Goovaerts, 1997). A relatively smooth variation of nugget, sill, and range parameters, such as shown in figure 16, ensures that order-relation corrections in the resulting kriging estimates are minimized and that the mIK-estimated local CFDs will accurately reflect local data dispersion (Deutsch and Journel, 1998). Note that the indicator variogram ranges inferred for layer A (5,000 to 50,000 ft) bracket the 20,000-25,000 value deduced for composite units 4 and 5 which comprise the bulk of layer A, as expected for a second-order stationary variable (Goovaerts, 1997). The autocorrelation ranges tend to be higher at higher thresholds, that is, where thicker accumulations of sediment extend over larger geographic areas. These nuggets, sills and ranges were subsequently used in multiple indicator kriging to define local CFDs at each kriging location.

\section{Kriging Approach}

Kriging relies on data within a nearest-neighbor search area to make estimates at unsampled locations on the basis of the autocorrelation structure of the data. Ideally, where sampling density is high, locally-defined variograms may be calculated solely on the basis of the neighboring data (Whelan and others, 2001), but in most environmental and subsurface situations, data density is almost never sufficient to permit such an approach and a global variogram must be inferred from the entire data set. Evidence of statistical stationarity is then used to justify the relevance of the global variogram to all local neighborhoods where kriging estimates are to be made. In this study, evidence for stationarity was based on the similarity of medians within different geographic portions of each model layer as well as on the autocorrelation structure of their indicator variograms and of the composite units' variograms.

Multiple indicator kriging was performed with the GSLIB $^{\text {TM }}$ software package (Deutsch and Journel, 1998). Indicator variogram parameters were defined at sediment thresholds of $1,3,5,7,9$, and 11 percent for all layers, as well as at thresholds of 18 and 25 percent for layer B and 20, 40 , and 60 percent for layer C. Linear tail approximations were used to approximate the CFD above the highest indicator threshold considered (fig. 14). Even though the maximum range of the indicator variograms was about $60,000 \mathrm{ft}$ (fig. 16), a kriging search radius of 150,000 ft was used to return estimates in even the most data-poor regions of each model layer. The disadvantage of this approach is that unsubstantiated estimates can arise in data-poor areas (reflecting simple averages of distant data values), but it is the only way to generate estimates over the entire domain. If preferred, such artifacts could be filtered and removed using a relative variance criterion (such as that generated by ordinary kriging; Isaaks and Srivastava, 1989) or assigned a reduced confidence level.

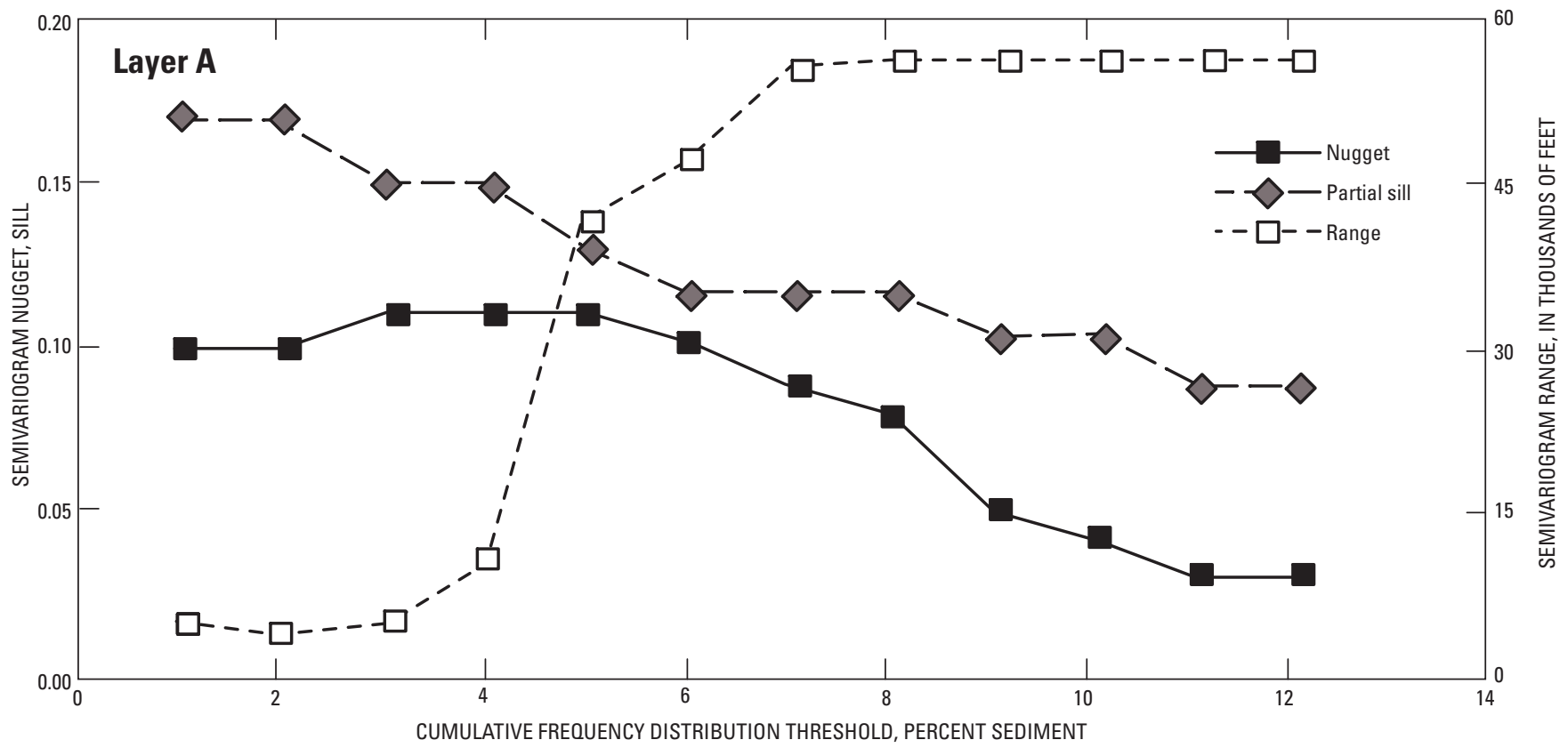

Figure 16. Results of multiple indicator variogram analysis for layer $A$, showing the progressive change in autocorrelation structure across a range of indicator thresholds. 


\section{Kriging Results}

\section{Multiple Indicator Kriging}

The median sediment contents of each layer (as read from the local CFDs estimated by $\mathrm{mIK}$ ) are shown in figure 17, in relation to the surface extent of the Big Lost Trough depositional basin (dashed polygon; after Geslin and others, 1999). Estimation variances also can be determined from the local CFDs, but they do not directly reflect the relative uncertainty that arises from the proximity of neighboring data
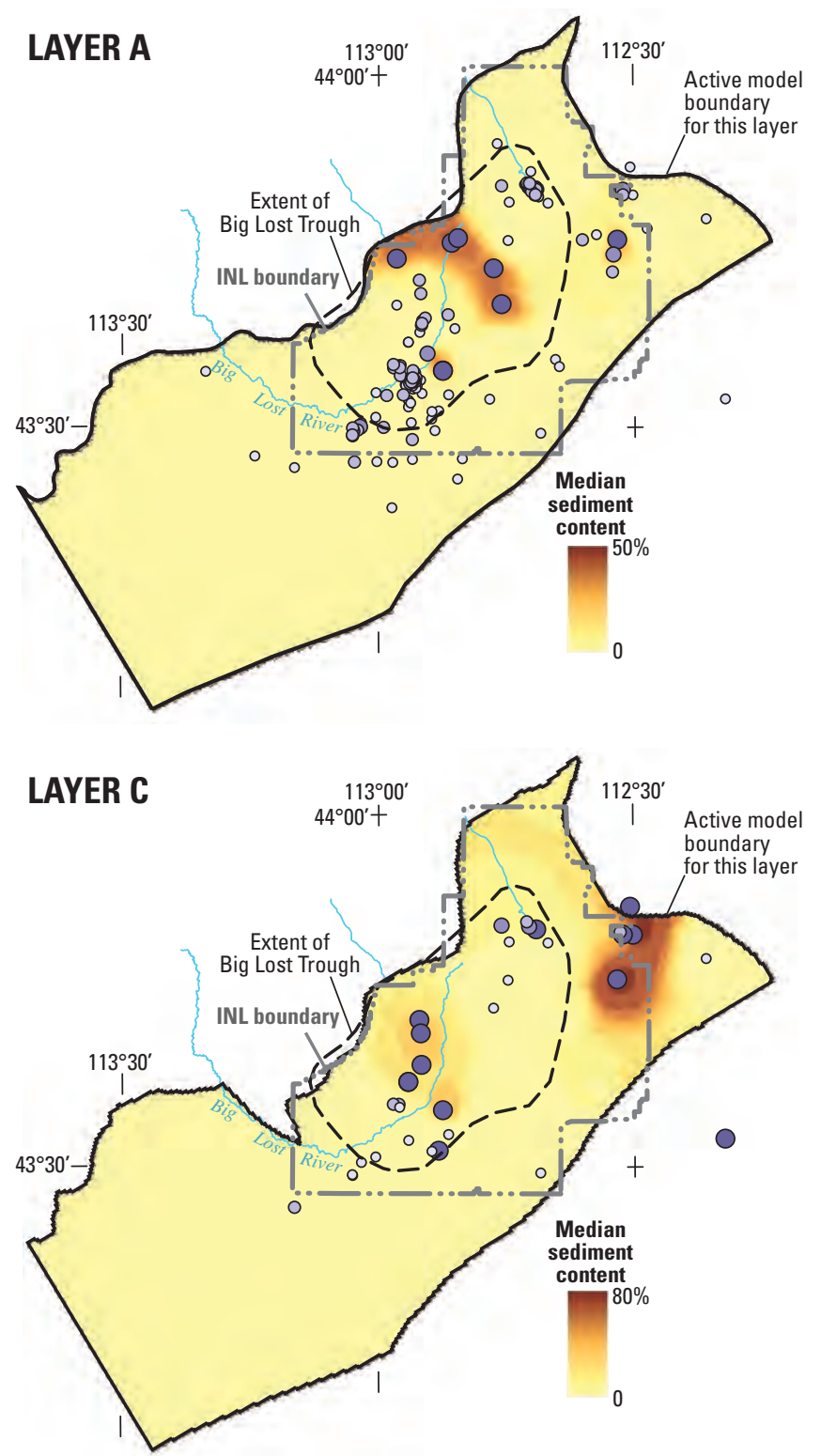

values. Because the latter is a far more important criterion when kriged sediment content is used to constrain hydraulic conductivity estimates, kriging uncertainty was quantified using the ordinary kriging variance rather than the local CFD variance returned by $\mathrm{mIK}$. A global variogram of the untransformed data in each layer (with a nugget of 0 and normalized to a sill of 1.0) was used to generate maps of ordinary kriging variance, $\sigma_{\mathrm{OK}}^{2}$ (for example, figure 18). The ordinary kriging variance provides a quantitative basis for classifying the modeled sediment abundance according to the uncertainty in data-poor areas relative to data-rich areas.

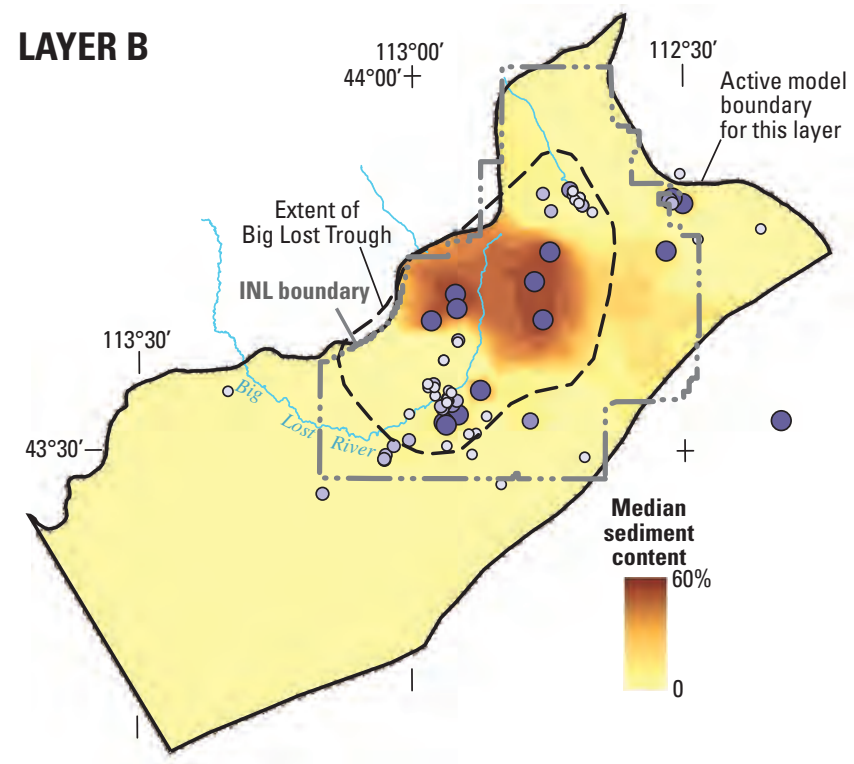

\section{EXPLANATION}

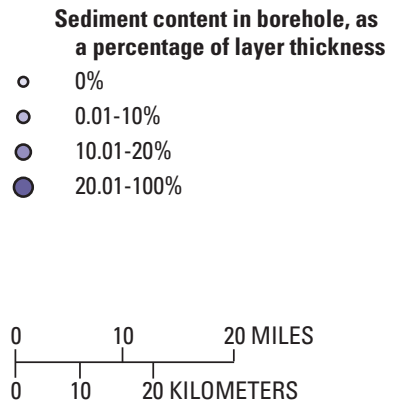

Base from U.S. Geological Survey digital data, 1:24,000 and 1:100,000 Albers Equal-Area Conic projection Standard parallels $42^{\circ} 50^{\prime} \mathrm{N}$ and $44^{\circ} 10^{\prime} \mathrm{N}$, central meridian $113^{\circ} 00^{\prime} \mathrm{W}$

Datum is North American Datum of 1927

Figure 17. Median percentage of sediment derived from multiple indicator kriging of layers A, B, and C. Percentages are equivalent to thickness, in feet, within each 100 -foot thick layer. 

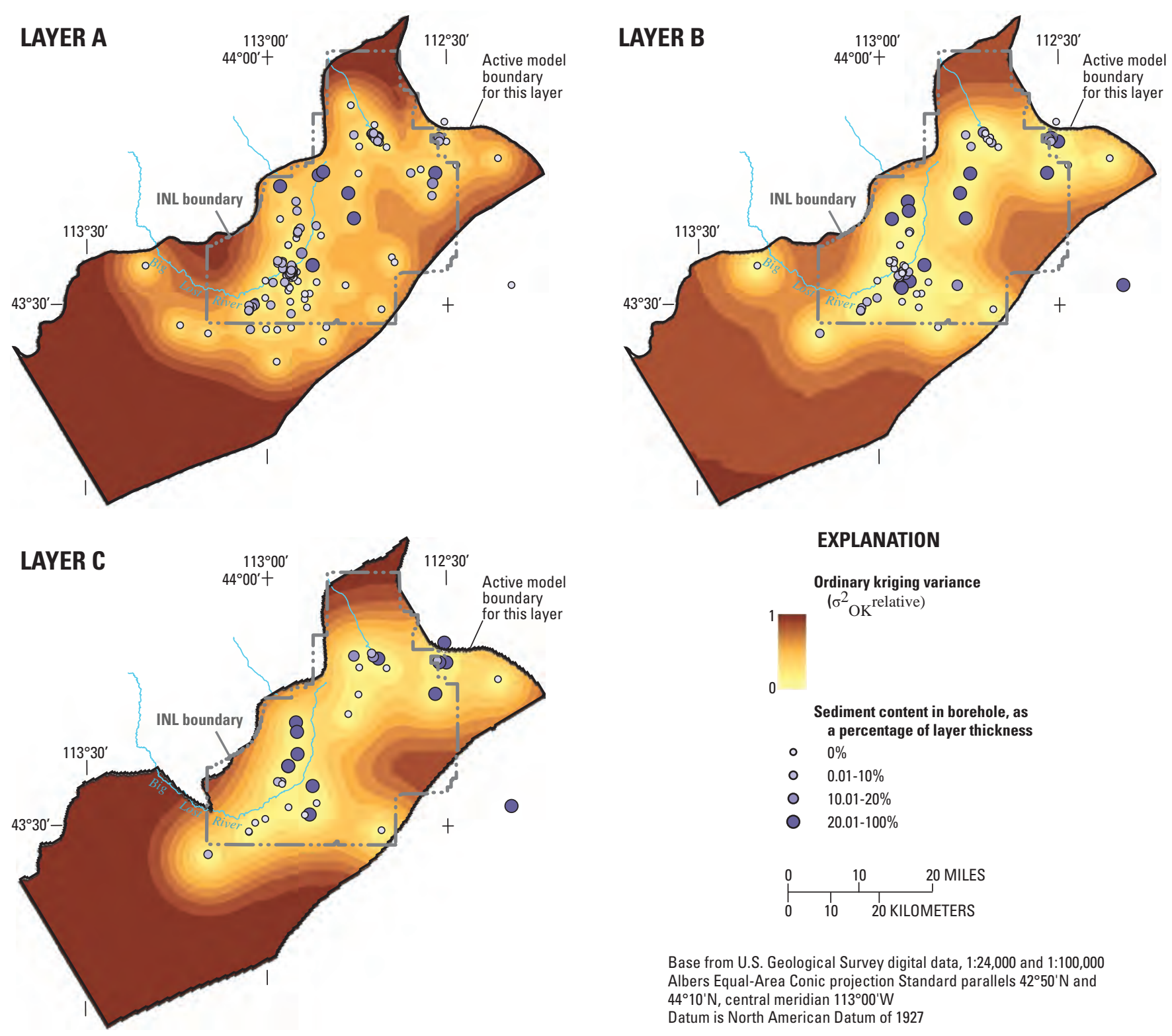

\section{EXPLANATION}
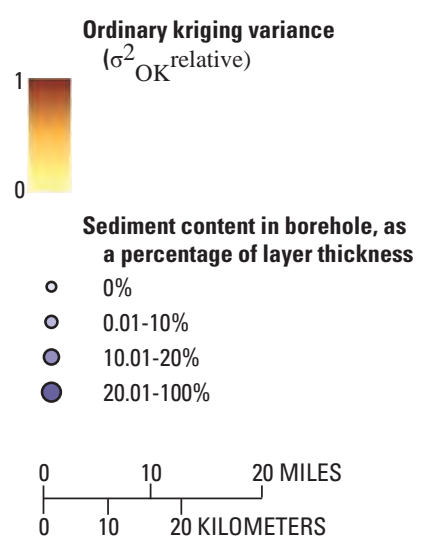

Base from U.S. Geological Survey digital data, 1:24,000 and 1:100,000 Albers Equal-Area Conic projection Standard parallels $42^{\circ} 50^{\prime} \mathrm{N}$ and $44^{\circ} 10^{\prime} \mathrm{N}$, central meridian $113^{\circ} 00^{\prime} \mathrm{W}$

Datum is North American Datum of 1927

Figure 18. Ordinary kriging variance $\left(\sigma_{\mathrm{OK}}^{2}\right)$ in layers $A, B$, and $C$, reflecting the relative uncertainty of kriging estimates based on the availability and arrangement of borehole data.

\section{Geohydrologic Implications}

Figure 17 shows the highest sediment contents in layers A and B generally occur within the boundary of the Big Lost Trough as delineated by Geslin and others (1999). For layer C, substantial thicknesses of sediment are detected outside the boundary, notably to the east of the depositional basin, indicating that the Big Lost Trough's spatial extent may have changed over time, possibly in response to volcanic construction.

The predicted distribution of sediment within individual layers bears little resemblance to the spatial extents of sediment-rich and sediment-poor areas currently implemented in the USGS subregional flow model. A map (fig. 19) of the subregional flow model's sediment-rich and sediment-poor areas, (Ackerman and others, 2006), shows the boundary between sediment-rich and sediment-poor areas inferred from borehole data collected from the uppermost $300 \mathrm{ft}$ of the aquifer, regardless of depth. Their classification is based on an 11-percent sediment classification threshold (fig. 5A). Figure $19 B$ shows the combined mIK results for the model layers recalculated as the median sediment content of the uppermost $300 \mathrm{ft}$ of the aquifer. The mIK model provides a refined picture of the spatial distribution of sediment in the upper part of the aquifer, by representing it on a layer-by-layer basis and reflecting greater confidence in areas with the most borehole control. 

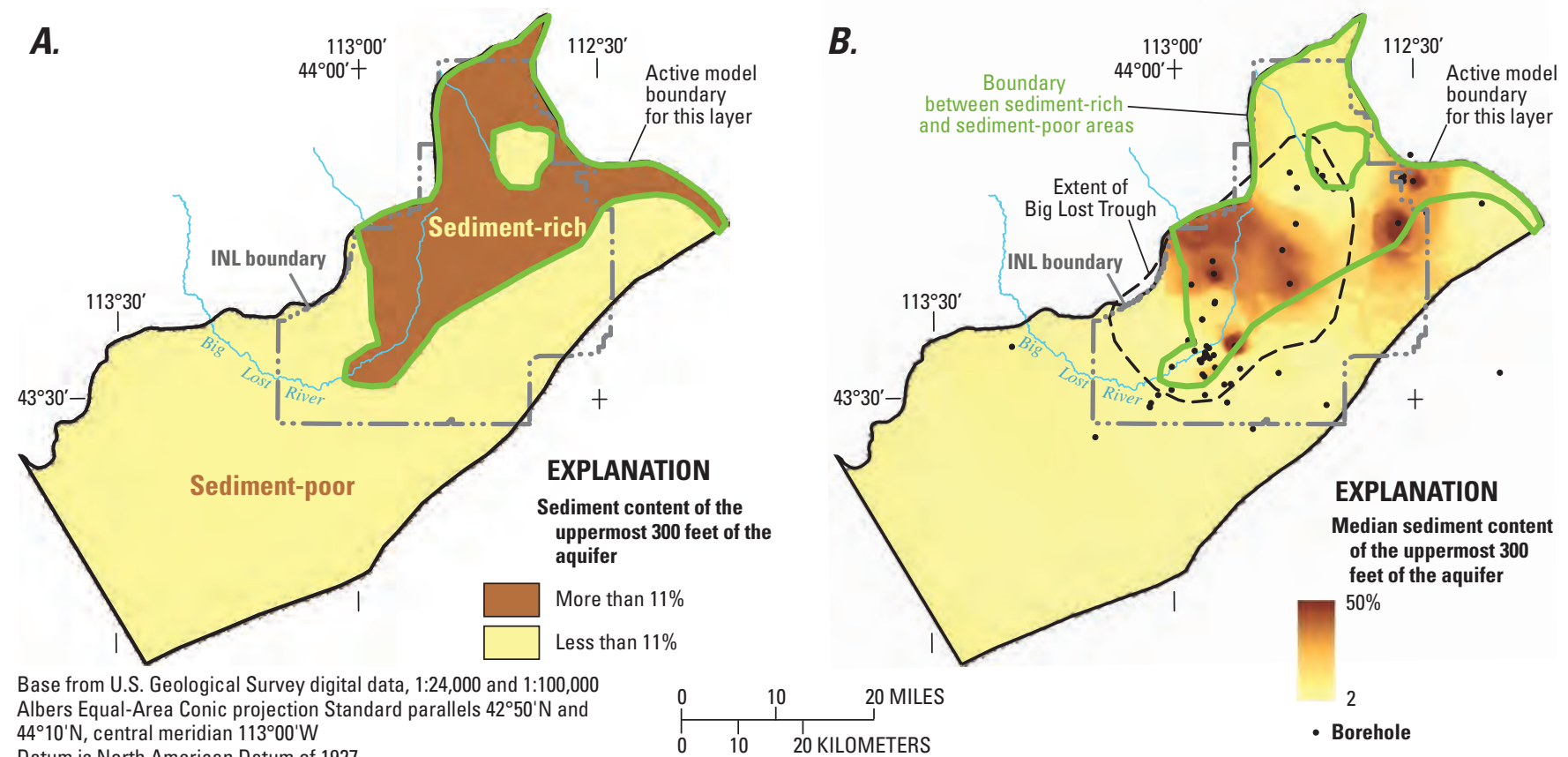

Base from U.S. Geological Survey digital data, 1:24,000 and 1:100,000 Albers Equal-Area Conic projection Standard parallels $42^{\circ} 50^{\prime} \mathrm{N}$ and $44^{\circ} 10^{\prime} \mathrm{N}$, central meridian $113^{\circ} 00^{\prime} \mathrm{W}$

Datum is North American Datum of 1927

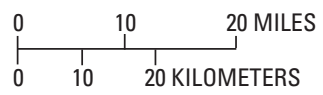

Figure 19. Distribution of sediment-rich and sediment-poor areas in the model domain. $(A)$ as currently implemented in the U.S. Geological Survey subregional ground-water flow model, based on an 11-percent sediment threshold, regardless of depth; and $(B)$ median sediment content of the uppermost 300 feet of the aquifer, as determined by multiple-indicator kriging. The extent of the Big Lost Trough (dashed polygon) and the boundary between sediment-rich and sediment-poor areas in $(A)$ are shown for comparison.

\section{Application to Scaling of Aquifer Hydraulic Conductivity}

The USGS modeling team has shown that optimized hydraulic conductivity values assigned during calibration of the subregional ground-water flow model tend to scale proportionately with zones of high- and low-sediment abundance shown in figure 19A (D.J. Ackerman, U.S. Geological Survey, oral commun., 2005). That is, the calibration process tends to assign lower values of hydraulic conductivity where sediment comprises more than 11 percent of the aquifer's uppermost $300 \mathrm{ft}$. Similar relations between aquifer hydraulic properties and sediment abundance have been noted for calibrated vertical:horizontal anisotropy ratios and specific yields (D.J. Ackerman, U.S. Geological Survey, oral commun., 2005). However, the coarse sediment zonation currently implemented in the subregional flow model introduces undesirable modeling artifacts, such as streamline refraction across a zonal boundary where hydraulic properties change abruptly (G.W. Rattray, U.S. Geological Survey, written commun., 2005).
The enhanced spatial resolution of the mIK models allows us to consider more sophisticated approaches to the scaling of hydraulic properties that depend on sediment content. Two types of methodologies are proposed: (1) those based solely on a threshold sediment content, such as the median, and (2) those based on a combination of a threshold and the uncertainty associated with the threshold estimate. In what follows, we consider hydraulic conductivity as an example of how scaling can be implemented, although similar lines of reasoning could be developed for porosity, storativity or any property whose values differ sufficiently between pure sediment and pure basalt.

Scaling involves expressing hydraulic conductivity as a function of the aquifer's sediment content, such as its median value (or some other, operationally defined level like the 11-percent threshold currently implemented in the USGS model). In a horizontally layered aquifer composed of fractured, high-permeability basalt and fine-grained, lowpermeability sediment, the vertical and horizontal components of hydraulic conductivity (or, more precisely, the components 
of hydraulic conductivity parallel and normal to layering) can be expressed as a function of the relative thicknesses of the two lithologies (Freeze and Cherry, 1979):

$$
K_{H}=\left[Z_{50} \cdot K_{S}+\left(100-Z_{50}\right) \cdot K_{B}\right] / 100
$$

and

$$
K_{V}=100 /\left[Z_{50} / K_{S}+\left(100-Z_{50}\right) \cdot K_{B}\right] / 100
$$

where

$K_{S}$ is the hydraulic conductivity of sediment;

$K_{B}$ is the hydraulic conductivity of basalt;

$Z_{50}$ is the median $\left(50^{\text {th }}\right.$ percentile $)$ sediment content;

$K_{H}$ and are the resulting components of hydraulic

$K_{V} \quad$ conductivity.

A threshold other than the median could also serve as the scaling variable. For example, at the 11-percent threshold currently implemented in the USGS subregional flow model, a relative bulk hydraulic conductivity can be estimated from the probability, $P_{11}$, of not exceeding the 11-percent sediment threshold (the threshold currently implemented in the subregional model):

$$
K_{\text {bulk }}=\left[\left(1-P_{11}\right) \cdot K_{S}+P_{11} \cdot K_{B}\right] .
$$

Examples of two mIK-derived local CFDs in a sedimentpoor and a sediment-rich location of layer A are shown in figure 20, having median sediment contents of $Z_{50-1}=$ 4 percent and $Z_{50-2}=36$ percent, respectively. For values of $K_{S}=0.2 \mathrm{ft} / \mathrm{d}$ and $K_{S}=11,000 \mathrm{ft} / \mathrm{d}$ (Garabedian, 1989), equation 2 results in $K_{H-1}=10,500 \mathrm{ft} / \mathrm{d}$ and $K_{H-2}=7,000 \mathrm{ft} / \mathrm{d}$; corresponding $K_{V}$ values derived from equation 3 are 5.0 and $0.6 \mathrm{ft} / \mathrm{d}$. The resulting anisotropy ratios $\left(K_{H} / K_{Y}\right)$ range from 2,100:1 to $13,000: 1$, similar to those obtained in the flow model calibration process (4,000:1 to $15,000: 1$; D.J. Ackerman, oral commun., 2005).

Using equation 4 , with values of $P_{11-1}=0.92$ and $P_{11-2}=$ 0.32 , and the same $K_{S}$ and $K_{B}$ values, the calculated values of $K_{\text {bulk }}$ at sites 1 and 2 are 10,100 and 3,500 ft/d, respectively.

Figure 21 illustrates how such a sediment-based scaling approach could be used to delineate hydraulic conductivity zones for zone-based parameter estimation. Although only three zones are considered in this illustration, any number could be defined. The mIK median sediment contents were classified into three categories (0-5-, 5-20-, 20-50-percent sediment) and hydraulic conductivity values representing the midpoints of those ranges were calculated from equations 2 and 3 . The resulting values are displayed as color-classified maps of $K_{H}$ and $K_{H} / K_{V}$ in figure $21 A$ and $\underline{21 B}$, respectively. Similarly, local CFD $p$-quantiles representing the mid-points
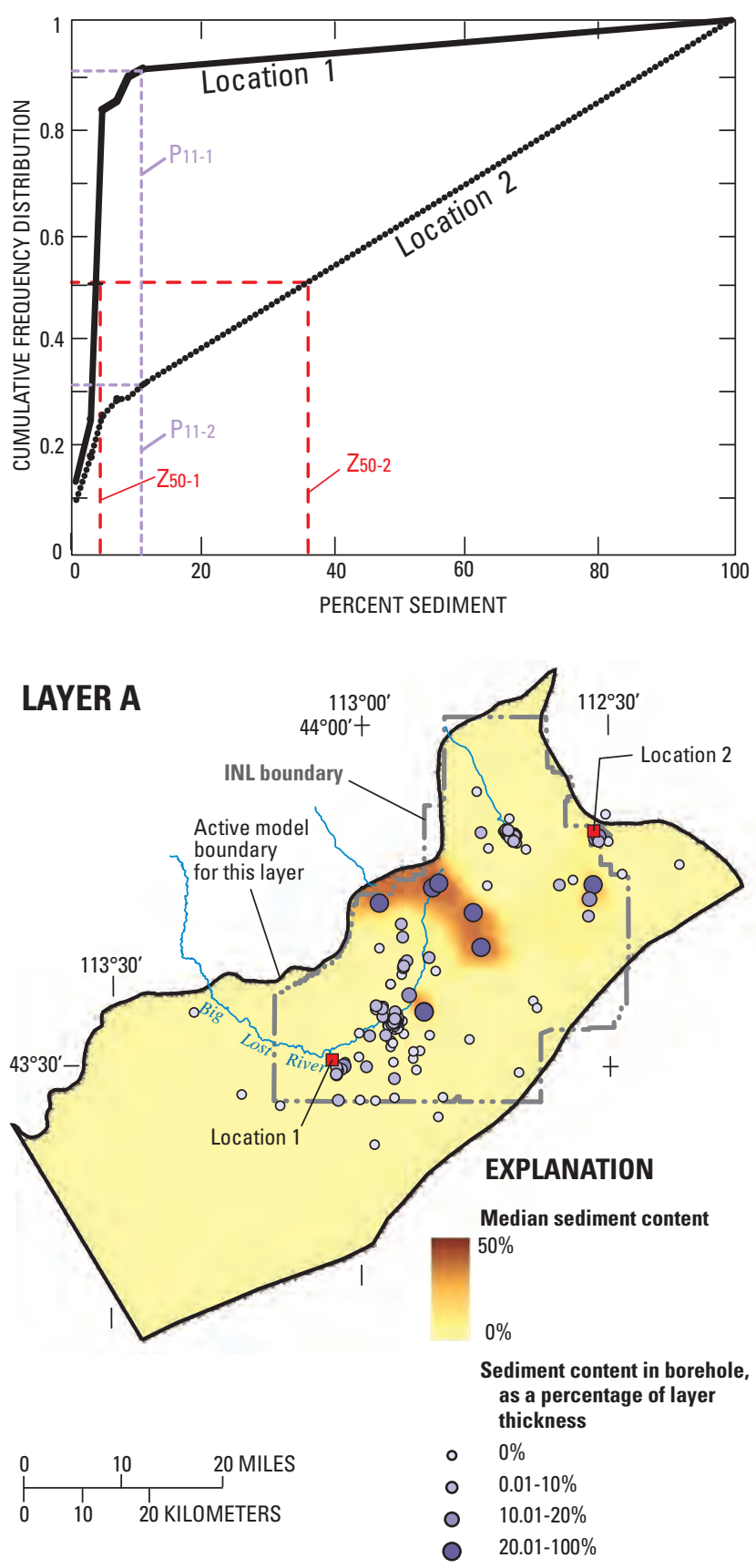

Base from U.S. Geological Survey digital data, 1:24,000 and 1:100,000 Albers Equal-Area Conic projection Standard parallels $42^{\circ} 50^{\prime} \mathrm{N}$ and $44^{\circ} 10^{\prime} \mathrm{N}$, central meridian $113^{\circ} 00^{\prime} \mathrm{W}$

Datum is North American Datum of 1927

Figure 20. Comparison of local cumulative frequency distributions (CFDs) derived from multiple indicator kriging (mIK) at two locations in Layer $A$, representing locations with low (location 1) and high (location 2) estimation variance. Median sediment contents $\left(Z_{50}\right)$ computed from the local CFDs are used to estimate horizontal and vertical hydraulic conductivity with equations 2 and 3. Local CFD probabilities for an 11 percent sediment threshold were used to estimate bulk hydraulic conductivities with equation 4. 

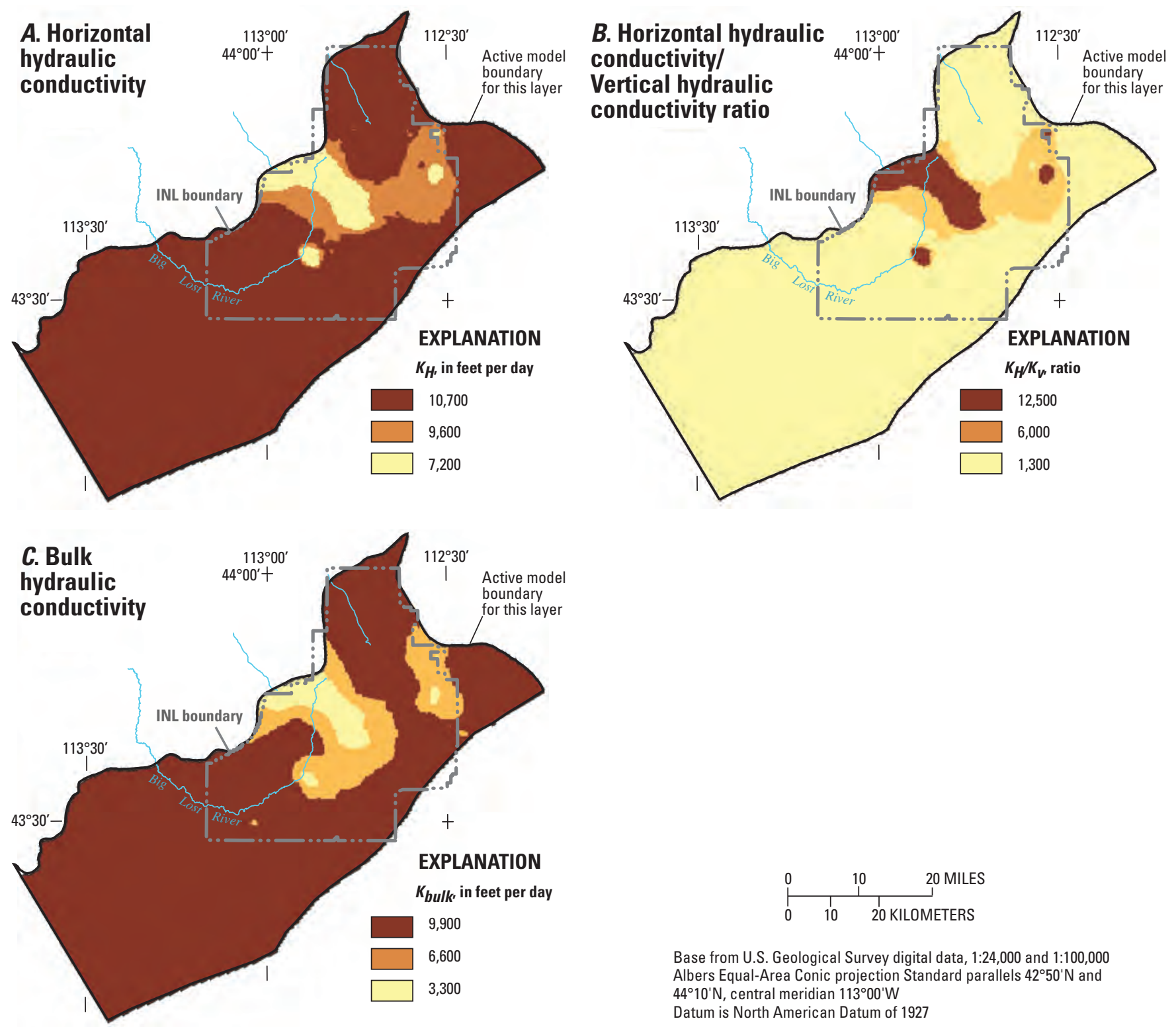

Base from U.S. Geological Survey digital data, 1:24,000 and 1:100,000 Albers Equal-Area Conic projection Standard parallels $42^{\circ} 50^{\prime} \mathrm{N}$ and $44^{\circ} 10^{\prime} \mathrm{N}$, central meridian $113^{\circ} 00^{\prime} \mathrm{W}$

Datum is North American Datum of 1927

Figure 21. Zones of hydraulic conductivity estimated from the kriged sediment content in layer $A$. $(A)$ horizontal hydraulic conductivity $\left(K_{H}\right)$ calculated as a weighted arithmetic mean of sediment and basalt end-members, using equation 2 with $K_{\text {basalt }}$ $=11,000$ and $K_{\text {sediment }}=0.2$ feet per day; $(B)$ the anisotropy ratio derived from $K_{H}$ and the vertical hydraulic conductivity $\left(K_{V}\right)$ calculated using equation 3 ; and $(C)$ bulk hydraulic conductivity $\left(K_{b u l k}\right)$ calculated as a weighted arithmetic mean, using equation 4 and the probability of not exceeding an 11-percent sediment threshold.

of the $P_{11}$ ranges (0.2-0.4), (0.4-0.8), and (0.8-1.0) were used in equation 4 to calculate values of $K_{b u l k}$ (fig. $21 C$ ). The resulting zone maps are applied in the same way that figure $19 \mathrm{~A}$ is used in the parameter estimation process.

During the parameter optimization process, it may be advantageous to allow $K$ values to vary more widely in areas where the zone boundaries are least certain. To achieve this, the zones defined in figure 21 can be further subdivided according to the kriging variance (fig. 18) into zones of low and high uncertainty. An example is shown in figure 22, where layer A's domain was classified around an ordinary kriging variance threshold of 0.6 on a relative scale of 0 to 1 . The hydraulic conductivity zones shown in figure $21 C$ were subsequently reclassified into five new categories representing areas of greater and lesser confidence in the scaled $K$ values. Such an approach would allow $K$ assignments during the calibration process to range more widely in zones of lower confidence. 


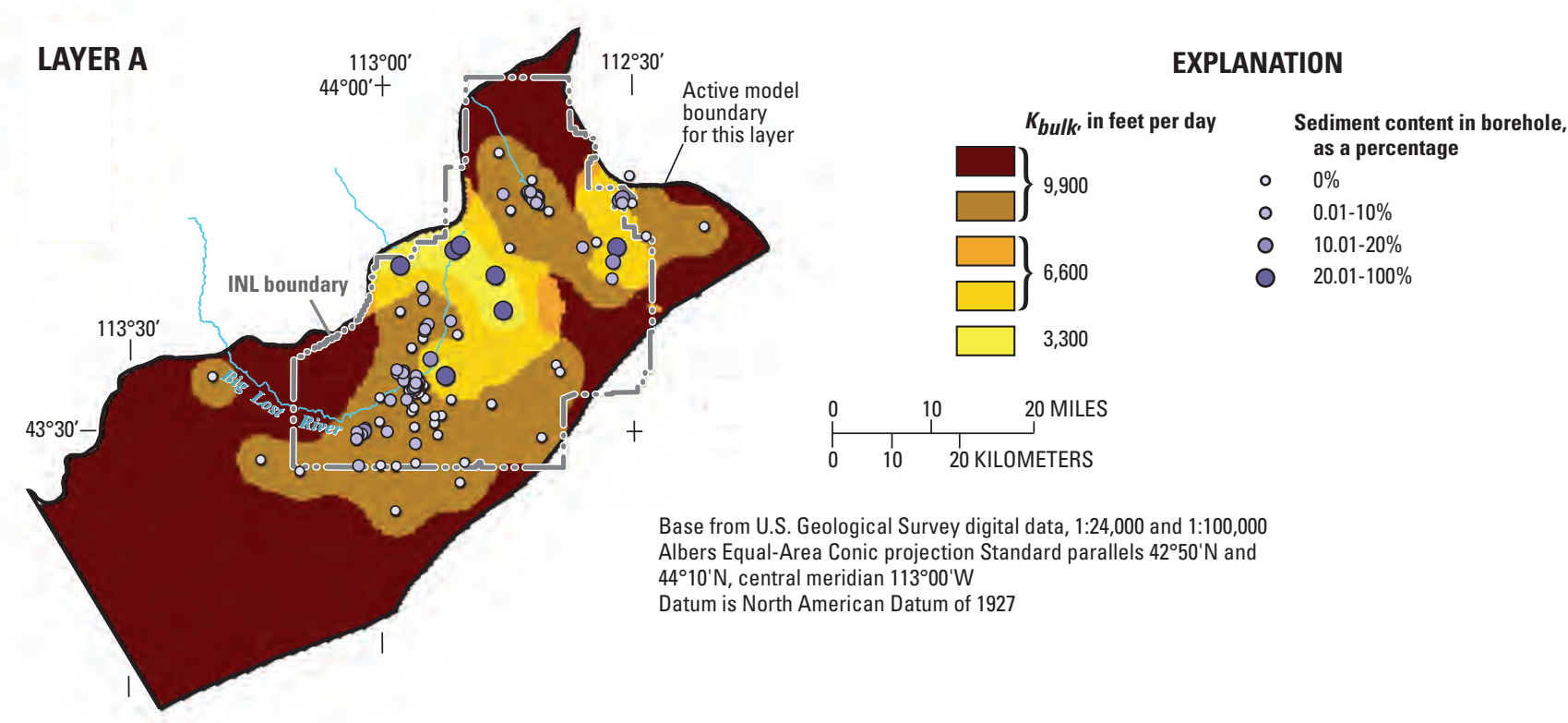

Figure 22. Layer A's bulk hydraulic conductivity $\left(K_{\text {bulk }}\right)$ classified according to the relative confidence in the kriged estimates as defined by the ordinary kriging variance (fig. 18, Layer A). Within each hydraulic conductivity zone, lighter colors indicate less uncertainty (better borehole control in data-rich areas) and darker colors indicate greater uncertainty in data-poor areas.

\section{Summary and Conclusions}

The relative sediment content of the eastern Snake River Plain aquifer is a key geologic variable that affects the assignment of hydraulic conductivity values during calibration of ground-water flow models. Geostatistical analysis was used to estimate sediment content in the uppermost $300 \mathrm{ft}$ of the U.S. Geological Survey (USGS) subregional ground-water flow model in order to improve future model calibrations.

The statistical characteristics of the sediment content of the aquifer, as measured in 333 boreholes located across the Idaho National Laboratory, were analyzed using conventional (nonspatial) and spatial statistical methods. Borehole data were segregated into various groups by stratigraphic age, depth, and geographic location in order to determine the degree of statistical stationarity that characterizes the model domain. The results indicate that the stratigraphic distribution of sediment within the aquifer, when evaluated over sufficiently large intervals of time (200 thousand years or greater), appears to be statistically stationary in a vertical sense as well as in a geographic sense. This finding makes it possible to model the spatial distribution of sediment in the uppermost three layers of the USGS subregional ground-water flow model using two-dimensional kriging within individual layers.
Multiple indicator variogram analysis and multiple indicator kriging $(\mathrm{mIK})$ were used to model the spatial distribution of sediment. The use of mIK has three principal advantages over ordinary kriging: (1) local uncertainty of the kriging estimate is quantified more accurately than is possible in ordinary kriging; (2) differing degrees of spatial autocorrelation can be used to describe sediment-rich and sediment-poor areas; and (3) local frequency distributions that characterize a layer's sediment contents can be used to delineate hydraulic-property zones that depend on sediment content.

The kriging approach honors all available borehole sediment data, provides better spatial resolution for delineating zones of relative sediment abundance, and provides a basis for making parameter assignments that reflect the uncertainty of the kriged sediment estimates. By delineating hydraulic conductivity zones with $\mathrm{mIK}$ and considering kriging uncertainty in the model calibration process, the ultimate benefit of such an approach will be to more tightly constrain parameter assignments in data-rich areas. This approach could be incorporated in future development of the USGS subregional ground-water flow model and development of methods for integrating the uncertainty associated with zonal boundaries into the parameter estimation process. 


\section{Acknowledgments}

We thank Joseph Rousseau of the U.S. Geological Survey (USGS) for his encouragement and support of this work, for his helpful comments as an informal reviewer, and for the opportunity to publish these results. We also thank Linda Davis (USGS) for assistance with the borehole database and GIS-related work, and Daniel Ackerman and Gordon Rattray of the USGS for sharing insights and data on the subregional flow model. We are especially grateful to Molly Leecaster ( $\mathrm{CH}^{2} \mathrm{M}$-Washington Group), John Nimmo (USGS), and Kip Bossong (USGS) for their thoughtful reviews that materially improved the manuscript and to Mary Hodges (USGS) for her comments as an informal reviewer. Finally, the senior author wishes to recognize co-author Steven Anderson for his work on elucidating the stratigraphic framework of the Eastern Snake River Plain, without which this study would not have been possible.

\section{References Cited}

Ackerman, D.J., 1991, Transmissivity of the Snake River Plain aquifer at the Idaho National Engineering Laboratory, Idaho: U.S. Geological Survey Water-Resources Investigations Report 91-4058 (DOE/ID-22097), 35 p.

Ackerman, D.J., Rattray, G.W., Rousseau, J.P., Davis, L.C., and Orr, B.R., 2006, A conceptual model of ground-water flow in the eastern Snake River Plain aquifer at the Idaho National Laboratory and vicinity with implications for contaminant transport: U.S. Geological Survey Scientific Investigations Report 2006-5122 (DOE-ID-22198), 62 p.

Anderson, S.R., 1991, Stratigraphy of the unsaturated zone and uppermost part of the Snake River Plain aquifer at the Idaho Chemical Processing Plant and Test Reactors Area, Idaho National Engineering Laboratory, Idaho: U.S. Geological Survey Water-Resources Investigations Report 91-4010 (DOE/ID-22095), 71 p.

Anderson, S.R., Ackerman, D.J., Liszewski, M.J., and Freiburger, R.M., 1996, Stratigraphic data for wells at and near the Idaho National Engineering Laboratory, Idaho: U.S. Geological Survey Open-File Report 96-248 (DOE/ID22127), 27 p. and 1 diskette.

Anderson, S.R., and Bartholomay, R.C., 1995, Use of naturalgamma logs and cores for determining stratigraphic relations of basalt and sediment at the Radioactive Waste Management Complex, Idaho National Engineering Laboratory, Idaho: Journal of the Idaho Academy of Science, v. 31, no. 1, p. 1-10.
Anderson, S.R., and Bowers, Beverly, 1995, Stratigraphy of the unsaturated zone and uppermost part of the Snake River Plain aquifer at Test Area North, Idaho National Engineering Laboratory, Idaho: U.S. Geological Survey Water-Resources Investigations Report 95-4130 (DOE/ID22122), 47 p.

Anderson, S.R., Kuntz, M.A., and Davis, L.C., 1999, Geologic controls of hydraulic conductivity in the Snake River Plain aquifer at and near the Idaho National Engineering and Environmental Laboratory, Idaho: U.S. Geological Survey Water-Resources Investigations Report 99-4033 (DOE/ID22155), 38 p.

Anderson, S.R., and Lewis, B.D., 1989, Stratigraphy of the unsaturated zone at the Radioactive Waste Management Complex, Idaho National Engineering Laboratory, Idaho: U.S. Geological Survey Water-Resources Investigations Report 89-4065 (DOE/ID-22080), 54 p.

Anderson, S.R., and Liszewski, M.J., 1997, Stratigraphy of the unsaturated zone and the Snake River Plain aquifer at and near the Idaho National Engineering Laboratory, Idaho: U.S. Geological Survey Water-Resources Investigations Report 97-4183 (DOE/ID-22142), 65 p.

Anderson, S.R., Liszewski, M.J., and Cecil, L.D., 1997, Geologic ages and accumulation rates of basalt-flow groups and sedimentary interbeds in selected wells at the Idaho National Engineering Laboratory, Idaho: U.S. Geological Survey Water-Resources Investigations Report 97-4010 (DOE/ID-22134), 39 p.

Barraclough, J.T., Robertson, J.B., Janzer, V.J., and Saindon, L.G., 1976, Hydrology of the solid waste burial ground, as related to the potential migration of radionuclides, Idaho National Engineering Laboratory: U.S. Geological Survey Open-File Report 76-471, (IDO 22056), 183 p.

Champion D.E., and Herman, T.C., 2003, Paleomagnetism of basaltic lava flows in coreholes ICPP-213, ICPP-214, ICPP-215, and USGS 128 near the Vadose Research Park, Idaho Nuclear Technology and Engineering Center, Idaho National Engineering and Environmental Laboratory, Idaho: U.S. Geological Survey Open-File Report 03-483, 15 p.

Champion, D.E., and Lanphere, M.A., 1997, Age and paleomagnetism of basaltic lava flows in corehole ANLOBS-AQ-014 at Argonne National Laboratory-West, Idaho National Engineering and Environmental Laboratory: U.S. Geological Survey Open-File Report 97-700, 34 p.

Champion, D.E., Lanphere, M.A., and Kuntz, M.A., 1988, Evidence for a new geomagnetic reversal from lava flows in Idaho: Discussion of short polarity reversals in the Brunhes and late Matuyama polarity chrons: Journal of Geophysical Research, v. 93, p. 11667-11680. 
Champion, D.E., Lanphere, M.A., Anderson, S.R., and Kuntz, M.A., 2002, Accumulation and subsidence of late Pleistocene basaltic lava flows of the eastern Snake River Plain, Idaho, in Link, P.K., and Mink, L.L., eds., Geology, Hydrogeology, and Environmental Remediation: Idaho National Engineering and Environmental Laboratory, Eastern Snake River Plain, Idaho: Boulder, Colo., Geological Society of America, Special Paper 353, p. 175192.

Deutsch, C.V., and Journel, A.G., 1998, GSLIB: Geostatistical Software Library and User's Guide (2d ed.): New York, Oxford University Press, 340 p.

Freeze, R.A., and Cherry, J.A., 1979, Groundwater: Englewood Cliffs, N.J., Prentice-Hall, 604 p.

Garabedian, S.P., 1989, Hydrology and digital simulation of the regional aquifer system, eastern Snake River Plain, Idaho: U.S. Geological Survey Open-File Report 87-237, $151 \mathrm{p}$.

Gego, E.L., Johnson, G.S., Hankin, M.R., and Welhan, J.A., 2002, Modeling ground water flow and transport in the Snake River Plain aquifer: a stochastic approach, in Link, P.K., Mink, R., and Ralston, D., eds., Geology, hydrogeology and environmental remediation, Idaho National Engineering and Environmental Laboratory, eastern Snake River Plain, Idaho: Geological Society of America, Special Paper 353, p. 249-261.

Geslin, J.K., Link, P.K., and Fanning, C.M., 1999, Highprecision provenance determination using detrital-zircon ages and petrography of Quaternary sands on the eastern Snake River Plain, Idaho: Geology, v. 27, no. 4, p. 295-298.

Goovaerts, P., 1997, Geostatistics for natural resources evaluation: New York, Oxford University Press, 483 p.
Greeley, Ronald, 1982, The Snake River Plain, Idaho: Representative of a new category of volcanism: Journal of Geophysical Research, v. 87, p. 2705-2712.

Grimm Chadwick, Claire, 2004, Petrogenesis of an evolved olivine tholeiite and chemical stratigraphy of cores USGS 127, 128, and 129, Idaho National Engineering and Environmental Laboratory: Pocatello, Idaho State University, M.S. thesis, 100 p., 4 app.

Helsel, D.R., and Hirsch, R.M., 2002, Statistical methods in water resources: Techniques of Water-Resources Investigations of the United States Geological Survey, book 4, chap. A3, 510 p.

Isaaks, E.H., and Srivastava, R.M., 1989, An introduction to applied geostatistics: New York, Oxford University Press, $561 \mathrm{p}$.

Kuntz, M.A., Dalrymple, G.B., Champion, D.E., and Doherty, D.J., 1980, Petrography and paleomagnetism of volcanic rocks at the Radioactive Waste Management Complex, Idaho National Engineering Laboratory, Idaho, with an evaluation of potential volcanic hazards: U.S. Geological Survey Open-File Report 80-388, 63 p.

Lanphere, M.A., Champion, D.E., and Kuntz, M.A., 1993, Petrography, age, and paleomagnetism of basalt lava flows in coreholes well 80, NRF 89-04, NRF 89-05, and ICPP 123, Idaho National Engineering Laboratory, Idaho: U.S. Geological Survey Open-File Report 93-327, 40 p.

Lanphere, M.A., Kuntz, M.A., and Champion, D.E., 1994, Petrography, age, and paleomagnetism of basalt lava flows in coreholes at Test Area North (TAN), Idaho National Engineering Laboratory, Idaho: U.S. Geological Survey Open-File Report 94-686, 49 p. 
Leecaster, M.K., 2002, Geostatistic modeling of subsurface characteristics in the Radioactive Waste Management Complex region, Operable Unit 7-13/14: Idaho Falls, Idaho, U.S. Department of Energy, INEEL/EXT-02-00029, 26 p.

Leecaster, M.K., 2004, Fiscal year 2004 geostatistical modeling of lithologic characteristics in the Radioactive Waste Management Complex for OU 7-13/14: Idaho Falls, Idaho, U.S. Department of Energy, ICP/EXT-04-00494, $27 \mathrm{p}$.

Lindholm, G.F., and Vaccaro, J.J., 1988, Region 2, Columbia Lava Plateau, in Hydrogeology, Back, W., Rosenshein, J.S., and Seabar, P.R., eds.: Geology of North America, v. O-2, Decade of North American Geology, Boulder, Colo., Geological Society of America, p. 37-50.

Pannatier, Y., 1996, VARIOWIN: Software for Spatial Data Analysis in 2D: New York, Springer-Verlag, 91 p.

Reed, M.F., Bartholomay, R.C., and Hughes, S.S., 1997, Geochemistry and stratigraphic correlation of basalt lavas beneath the Idaho Chemical Processing Plant, Idaho National Engineering Laboratory: Environmental Geology, v. 30 , p. $108-118$.

Scarberry, K.C., 2003, Volcanology, geochemistry, and stratigraphy of the F basalt flow group, eastern Snake River Plain, Idaho: Pocatello, Idaho State University, M.S. thesis, $139 \mathrm{p}$.

Walker, G.P.L., 1974, Compound and simple lava flows and flood basalts. Bulletin of Volcanology 35, p. 579-590.
Welhan, J.A., and Reed, M.F., 1997, Geostatistical analysis of regional hydraulic conductivity variations in the Snake River Plain aquifer, eastern Idaho: Geological Society of America, Bulletin 109, p. 855-868.

Welhan, J.A., Clemo, T. and Gego, E., 2002a, Stochastic simulation of aquifer heterogeneity in a layered basalt aquifer system, eastern Snake River Plain, Idaho, in Link, P.K., Mink, R. and Ralston, D., eds., Geology, hydrogeology and environmental remediation, Idaho National Engineering and Environmental Laboratory, eastern Snake River Plain, Idaho: Geological Society of America Special Paper 353, p. 225-247.

Welhan, J.A., Johannesen, C.M., Reeves, K., Clemo, T., Glover, J.A., and Bosworth, K., 2002b, Morphology of inflated pahoehoe lavas and spatial architecture of their porous and permeable zones, eastern Snake River Plain, Idaho, in Link, P.K., Mink, R. and Ralston, D., eds., Geology, hydrogeology and environmental remediation, Idaho National Engineering and Environmental Laboratory, eastern Snake River Plain, Idaho: Geological Society of America Special Paper 353, p. 135-150

Whelan, B.M., McBratney, A.B., and Minasny, B., 2001, VESPER: Spatial prediction software for precision agriculture, in Grenier, G. and Blackmore, S., eds., Proceedings of the European Conference on Precision Agriculture: Montpelier, France, Agro-Montpelier, p. 139-144. 
This page is intentionally left blank. 
Manuscript approved for publication, December 9, 2006

Prepared by the USGS Publishing Network,

Publishing Service Center, Tacoma, Washington

Bill Gibbs

Bob Crist

Debra Grillo

Sharon Wahlstrom

Bobbie Jo Richey

For more information concerning the research in this report, contact the Director, Idaho Water Science Center

230 Collins Road

Boise, Idaho 83702

http://id.water.usgs.gov 


$$
\text { ख़ }
$$

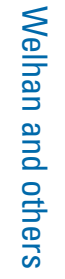

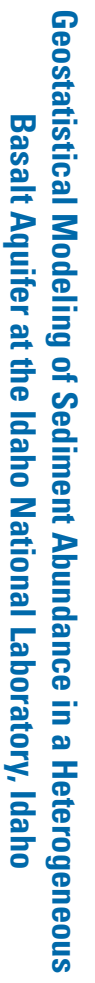

